\title{
Groundwater potentiality mapping using geoelectrical-based aquifer hydraulic parameters: A GIS-based multi-criteria decision analysis modeling approach
}

\author{
Kehinde Anthony Mogaji ${ }^{1,2, *}$ and Hwee San $\operatorname{Lim}^{2}$ \\ ${ }^{1}$ Department of Applied Geophysics, Federal University of Technology, Akure, Nigeria \\ ${ }^{2}$ School of Physics, Universiti Sains Malaysia, Penang, Malaysia.
}

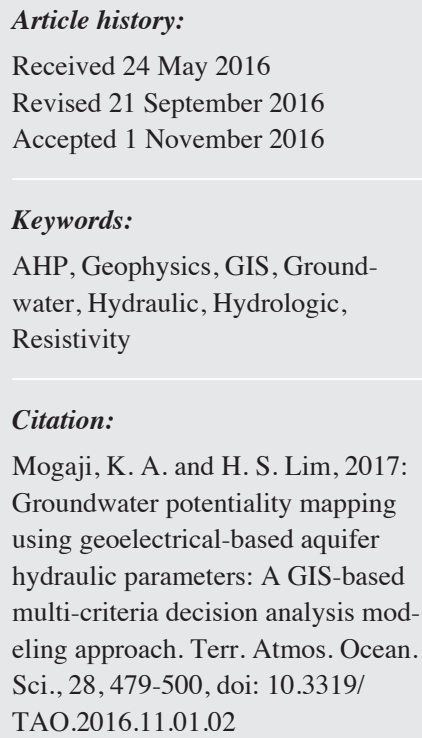

\begin{abstract}
This study conducted a robust analysis on acquired 2D resistivity imaging data and borehole pumping test records to optimize groundwater potentiality mapping in Perak province, Malaysia using derived aquifer hydraulic properties. The transverse resistance (TR) parameter was determined from the interpreted 2D resistivity imaging data by applying the Dar-Zarrouk parameter equation. Linear regression and GIS techniques were used to regress the estimated values for TR parameters with the aquifer transmissivity values extracted from the geospatially produced BPT recordsbased aquifer transmissivity map to develop the aquifer transmissivity parameter predictive (ATPP) model. The reliability evaluated ATPP model using the Theil inequality coefficient measurement approach was used to establish geoelectrical-based hydraulic parameters (GHP) modeling equations for the modeling of transmissivity (Tr), hydraulic conductivity (K), storativity (St), and hydraulic diffusivity (D) properties. The applied GHP modeling equation results to the delineated aquifer media was used to produce aquifer potential conditioning factor maps for Tr, K, St, and D. The maps were modeled to develop an aquifer potential mapping index (APMI) model via applying the multi-criteria decision analysis-analytic hierarchy process principle. The area groundwater reservoir productivity potential model map produced based on the processed APMI model estimates in the GIS environment was found to be $71 \%$ accurate. This study establishes a good alternative approach to determine aquifer hydraulic parameters even in areas where pumping test information is unavailable using a cost effective geophysical data. The produced map can be explored for hydrological decision making.
\end{abstract}

\section{INTRODUCTION}

Groundwater productivity potential mapping is one of the efficient means used to plan and manage groundwater hydrology exploration for both local and regional scale analysis (Lee et al. 2012). However, for efficient groundwater management planning, the quantitative description of aquifers is an integral means to achieve this task (Soupios et al. 2007). Ndatuwong and Yadav (2015) established that intensive studies on the geometry and properties of aquifers are essential to maximize these subsurface natural resources. Furthermore, quantitative evaluation of the various aquifer parameters along with aquifer potential zone mapping is a

\footnotetext{
* Corresponding author

E-mail:mogakeh@yahoo.com
}

laudable task to enhance accurate decision making in groundwater resource development (Ahmed et al. 2004). Thus, several aquifer hydraulic parameters, including transmissivity, hydraulic conductivity and others, have been determined to assess the favorability of aquifer conditions to groundwater productivity in an area (Soupios et al. 2007; Tizro et al. 2010; Ekwe et al. 2010; Adiat et al. 2013). Indisputably, with recurrent challenges particularly in the area of incremental demand for potable water resources for domestic, agricultural and industrial use, accurate modeling, and estimation of these aquifer parameters can greatly assist in harnessing maximum groundwater resources to solve existing problems.

In the literature, the renowned approach for assessing aquifer conditions involving quantitative evaluation of aquifer hydraulic properties in an area is through the borehole 
pumping test (BPT) analysis. According to Tizro et al. (2007), Oborie and Udom (2014), and Ugada et al. (2014), the productivity and appraisement of drilled groundwater holes is greatly achieved by employing the BPT approach. This BPT technique application aids in the optimal exploration of groundwater resources in the field of groundwater hydrology. However, the labor intensiveness and expense limitations associated with the BPT approach reduce applications of this technique in environmental studies. The indispensable field conditions and assumptions upon which the BPT approach efficiency is largely based are often disregarded during field measurements (Tizro and Singhal 1993). Consequently, the determination of aquifer hydraulic parameters through the BPT mechanism often involves errors. The resultant effect of such errors, particularly during regional prospectivity estimation on aquifer hydraulic parameters, is severe and inimical to accurate decision making with regard to environmental issues. Therefore, the objective of this study is to holistically investigate the application of geophysical and GIS-based multi-criteria techniques as another alternative to the BPT approach.

The geophysical technique is a noninvasive, cost-effective method that is highly relevant in subsurface investigation. This technique has gained widespread acceptance in groundwater resource exploration (Mohamed et al. 2013). Among several prospective geophysics methods, the directcurrent electrical resistivity (ER) method is the most highly efficient in groundwater studies. The probable reasons are its attributes of simplicity, robustness, and cost effectiveness (Vozoff and Jupp 1975; Koefoed 1979; Rubin and Hubbard 2005). One of the ER method practical applications in groundwater resource exploration is its efficient mapping and delineation of prolific aquifer formation (Oborie and Udom 2014). In addition, the ER method facilitates quantitative estimate of the water-transmitting properties of mapped aquifer units. From the Dar-Zarrouk parameter (DZP) modeling perspective, the geoelectrical parameters based on the ER method are used to determine aquifer hydraulic characteristics in porous media (Ekwe et al. 2006; Tizro et al. 2010). Furthermore, through empirical/semi-empirical correlations and linear regression technique applications, resistivity parameters are used in estimating aquifer transmissivity, formation factors, and aquifer formation permeability (Kelly 1977; Heigold et al. 1979; Schimschal 1981; Chen et al. 2001). The vertical electrical sounding (VES) geoelectrical technique is the most commonly used approach in the above mentioned studies on aquifer parameter estimation. According to Khalil et al. (2013), the VES technique is a 1D approach that assumes that the layered earth model is homogeneous and isotropic in nature. By inference, the VES technique does not consider the lateral changes in the earth layer resistivity and thus often causes ambiguity in subsurface characterization. However, a 2D resistivity imaging technique, which is a robust subsurface imaging model with high efficiency in subsurface characterization, has the ability to measure resistivity changes in both the vertical and horizontal directions. For instance, according to Loke and Barker (1996), Loke (2001), and Loke et al. (2003), the $2 \mathrm{D}$ resistivity imaging technique has higher resolution and provides a better approximation interpretation of the true subsurface geology compared with the VES 1D model technique. Thus, the $2 \mathrm{D}$ resistivity imaging technique has been explored in several hydrogeological studies, including those on groundwater pollution (Islami et al. 2012), salinity mapping (Pujari and Soni 2009; Sathish et al. 2011), and aquifer potential mapping (Ewusi et al. 2009; Asry et al. 2012). However, 2D resistivity imaging technique application in determining aquifer hydraulic parameters is very limited. The $2 \mathrm{D}$ resistivity imaging technique involvement in these aforementioned hydrogeological studies is purely for point-based 2D resistivity imaging data analysis and devoid of regional prospectivity analysis. Thus, the findings of these studies lack applicability in environmental decision making on a regional scale. To effectively process $2 \mathrm{D}$ imaging data for hydrogeological investigation, particularly for regional prospectivity estimation of aquifer hydraulic parameters, the $2 \mathrm{D}$ resistivity imaging data modeling concept through the GIS-based multi-criteria modeling technique is investigated in the field of groundwater hydrogeology. This proposed conceptual approach provides excellent insights into evaluating aquifer geometry underlying an area with the view of enhancing groundwater productivity potential prediction accuracy in an area of interest.

Scientific investigations documented a large number of multi-criteria decision methods (MCDM) such as the analytic hierarchy process (AHP), multi-attribute value function theory, multi-attribute utility function theory, and outranking methods (Chowdhury et al. 2009; Awasthi and Chauhan 2011). Among the itemized MCDM, the AHP technique has the unique attribute of allowing transitivity property verification in criteria weights that are often traceable to potential mapping decision making studies (Pazand et al. 2012). According to Chan et al. (2008), this technique is a decision analysis method that can combine both qualitative and quantitative information by decomposing their ill-structured problems into systematic hierarchies to rank alternatives based on a number of criteria. Furthermore, according to Ying et al. (2007), the AHP technique multi-index evaluation attribute gave it a special advantage in environmental studies. The AHP technique potential was widely explored in a number of investigations including groundwater potential prediction (Chowdhury et al. 2009; Jha et al. 2010; Adiat et al. 2012; Fashae et al. 2014), landfill site selection (Yal and Akgün 2013), tourism (Ghamgosar et al. 2011), agriculture (Montazar and Behbahani 2007), technology (Ariff et al. 2008), site selection (Vahidnia et al. 2009), and mineral exploration (De Araújo and Macedo 2002) with satisfactory results. However, the applied multi-criteria 
decision analysis (MCDA) technique efficiency in these aforementioned studies is greatly enhanced by employing the GIS technique. Notably, the AHP technique is efficient in resource potential prediction modeling, while the GIS technique has spatial analysis efficacy. The relevance of the GIS technique is that it offers the capability to efficiently manage and integrate large volumes of spatial and temporal data, which are crucial for successful analysis, prediction, and validation in solving spatial decision problems (Srivastava and Bhattacharya 2006; Chowdhury et al. 2009; Jha et al. 2010). Therefore, the hybrid approach for GIS and AHP techniques that efficiently combines multiple hydrological data to produce a reliable decision model will significantly enhances groundwater productivity potential assessment in an area of interest.

The main objective of this study is to synthesize relevant aquifer hydraulic parameters being determined from $2 \mathrm{D}$ resistivity imaging measurement to model groundwater potential zones through GIS-based AHP technique application. Such derived aquifer hydraulic parameters include transmissivity, hydraulic conductivity, storativity, and hydraulic diffusivity. The approach is illustrated using a case study in the southern part of Perak, Malaysia that evaluates and manages groundwater resources in the area. The study produces a groundwater reservoir productivity potential model (GRPPM) map validated with the actual borehole yield data obtainable in the area. This study also generated a linear regression model equation with high predictive power accuracy that enables determining transmissivity and its variation from place to place, including areas where no boreholes exist.

\section{GEOGRAPHY, HYDROLOGY, AND HYDROGEOLOGY OF STUDY AREA}

The study area is situated between the boundary of Perak and Selangor in Peninsular Malaysia (Fig. 1a). Figure 1b presents the $2848 \mathrm{~km}^{2}$ study area showing other important features. The site lies between longitudes $101^{\circ} 0$ ' $\mathrm{E}$ and $101^{\circ} 40^{\prime} \mathrm{E}$ and between latitudes $3^{\circ} 37^{\prime} \mathrm{N}$ and $4^{\circ} 18^{\prime} \mathrm{N}$ in the southern part of Perak. The geological area is underlain with diverse rock types, namely, alluvium, sedimentary and acidic undifferentiated granitoid rocks (Fig. 1c). Through the qualitative interpretation of the available borehole lithologs (Fig. 1d) obtained from the Malaysian Department of Minerals and Geosciences, the insights into the subsurface hydrogeological analysis of these aforementioned rock types were investigated. The delineated aquifer unit underlying the quaternary rock formation was observed to have sand, gravel, silt and a thick column of clay, referred to as aquitard, as its constituent (Minerals and Geoscience Department, Malaysia 2004). The constituent and nature of the aquifer unit delineated on the Devonian rock has more clay than sand. The Silurian rock, on the other hand, has mostly confined aquifer units because of low permeability soil column, i.e., weathered shale and large amounts of clay. The acidic and undifferentiated granitoid geological formation is a crystalline rock that is associated with granite and Terolak Formation metasediment contact. Fractures within the crystalline rocks form the aquifer unit and have a dual aquifer nature that is confined and unconfined. Generally, the areaunderlain aquifers are more confined than unconfined. With these different geological settings, the area groundwater storage potentiality is highly varied. These variations, according to Satpathy and Kanungo (1976) and Mohamed et al. (2013), are often caused by localization or discontinuity in aquifer formation on a regional scale. Thus, the perspective of studying aquifer geometry through estimation and prediction of the relevant hydraulic parameters will greatly enhances accurate decision making in groundwater resources development in a multifaceted geologic environment. The region is also characterized by an equatorial maritime climate with nearly uniform air temperatures throughout the year. The average daily temperature is approximately $27^{\circ} \mathrm{C}$ and the relative humidity has a monthly mean value of 62 and $78 \%$ for the dry period and peak in the rainy season, respectively. The regional topographic elevation variation in the area is in the range of $79-2131 \mathrm{~m}$ as extracted from the world topographic map. The general annual precipitation in Perak state ranges from $830-3000 \mathrm{~mm}$.

\section{MATERIALS AND METHODOLOGY}

The materials used in this study encompass the obtained BPT measurement data and the field acquired geophysical data. Figure 2 presents an overview of the approaches adopted for the regional assessment of the groundwater reservoir potential productivity mapping in the study area. These approaches were implemented at eight different phases. Phase 1 entails (1) pumping test analysis of the groundwater reservoir potentiality characteristics in the area, (2) BPT measured aquifer yield analysis, and (3) the BPT measured aquifer transmissivity analysis. Phase 2 involved an investigation into the regional field geophysical prospect. At this phase, (1) 2D resistivity imaging geophysical data acquisition, processing, and interpretations were conducted and (2) DZP was determined from the interpreted geoelectrical parameters [layer thickness (h) and layer resistivity $(\rho)]$. The GIS tools application constituted phase 3. At this phase, (1) the borehole aquifer transmissivity map was generated and (2) an overlay and spatial analyses involving the produced borehole aquifer transmissivity map and the determined transverse resistance (TR) values were conducted. Phase 4 applied the linear regression technique in aquifer transmissivity parameter predictive (ATPP) model equation development. Phase 5 deals with aquifer potential productivity conditioning factors (APPCFs) map production. AHP-MCDA was applied to model APPCFs for groundwater potential 

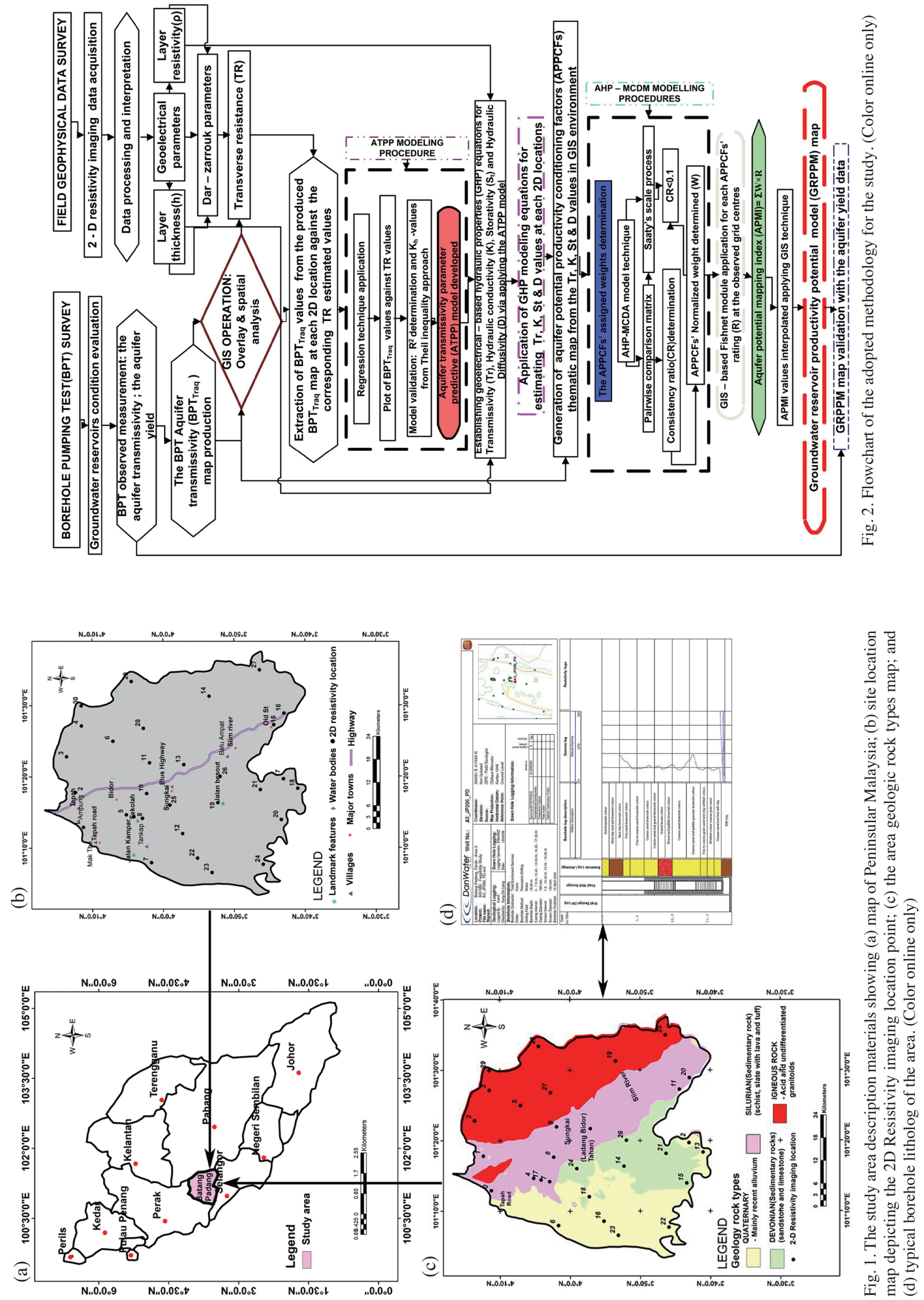
mapping in phase 6 . The aquifer potential mapping index (APMI) model development for the area is staged at phase 7 . Phase 8 applied the developed APMI model to produce the GRPPM area map and its validation to ascertain its prediction accuracy using the observed well yield data from the area. The details of these aforementioned phases are highlighted in the following subsections.

\subsection{BPT Survey Inventory}

\subsubsection{Pumping Test Analysis of Groundwater Reservoir Area Potentiality Characteristics}

A reconnaissance study to assess the groundwater area occurrence potentialities through quantitative appraisal of the yield and transmissivity properties of the drilled boreholes in the area using the BPT survey technique was conducted by the Malaysian Department of Minerals and Geosciences Board. The survey borehole inventory in the area is shown in Fig. 3. The obtained BPT measurement database were analyzed for aquifer yield and transmissivity parameters across 28 drilled holes to quantitatively gain insight into the in situ hydraulic properties of the area underlain aquifer formation. Such information provides a complete and accurate groundwater potentiality that characterizes the given study area.

\subsubsection{Analysis of BPT-Measured Aquifer Yield Record and its Transmissivity Values}

In the area-acquired BPT database, the available yield and transmissivity value records were analyzed across the occupied 28 borehole locations (Fig. 3). The observed aquifer yield in the area is in the range of $0.39-43.71 \mathrm{~m}^{3} \mathrm{~h}^{-1}$ (see column 4 of Table 1). The aquifer transmissivity property values of the area borehole, on the other hand, varies between 0.001 and $0.15 \mathrm{~m}^{2} \mathrm{~s}^{-1}$ in column 5 . However, the BPT records measured aquifer transmissivity $\left(\mathrm{BPT}_{\mathrm{Traq}}\right)$ values in column 5 of Table 1 were converted into square meters per day values in column 6 with values in the range of 86.4 $13227.8 \mathrm{~m}^{2}$ day $^{-1}$ using the conversion factor of 86400 . As shown in Table 1 the observed values from these measured aquifer hydraulic parameters show a degree of variation that is largely space dependent in the study area.

\subsection{Geophysical Technique Application Approach}

\subsubsection{D Resistivity Imaging Data Acquisition, Processing, and Interpretation}

To assess the groundwater area reservoir characteristic potentialities on a regional scale, the noninvasive geophysical prospecting technique was regionally deployed. Thus, this study employed the $2 \mathrm{D}$ resistivity imaging technique with the use of modern field equipment ABEM SAS 4000 to acquire geophysical data on the evenly distributed 30 loca- tion points as depicted in Fig. 1b. The established located points were combed using both Wenner-Schlumberger and Schlumberger arrays, and data were recorded automatically on each observed location point at each electrode station. The obtained data on each occupied location were processed and inverted using the RES2DINV software developed by Loke and Barker (1996). The software uses a least-squares optimization technique to invert the 2D-acquired apparent resistivity pseudo sections to define true resistivity distribution in the subsurface (Sasaki 1992; Loke 2004). The leastsquares optimization minimizes the square of the differences between the observed and calculated apparent resistivity values. The program automatically creates a $2 \mathrm{D}$ model by dividing the subsurface into rectangular blocks (Loke 2004), and the resistivity of the blocks is iteratively adjusted to reduce the difference between the measured and calculated apparent resistivity values. The program calculates the apparent resistivity values and compares these to the measured data. During the iteration, the modeled resistivity values are adjusted until the calculated apparent resistivity values of the model agree with the actual measurements. The iteration is stopped when the inversion process converges, that is, when the root mean square error (RMSE) either falls to acceptable limits or when the change between the RMSE in consecutive iterations becomes negligible. However, before the geoelectric parameters were determined, the subsurface layers are first delineated. The lithology unit boundary in

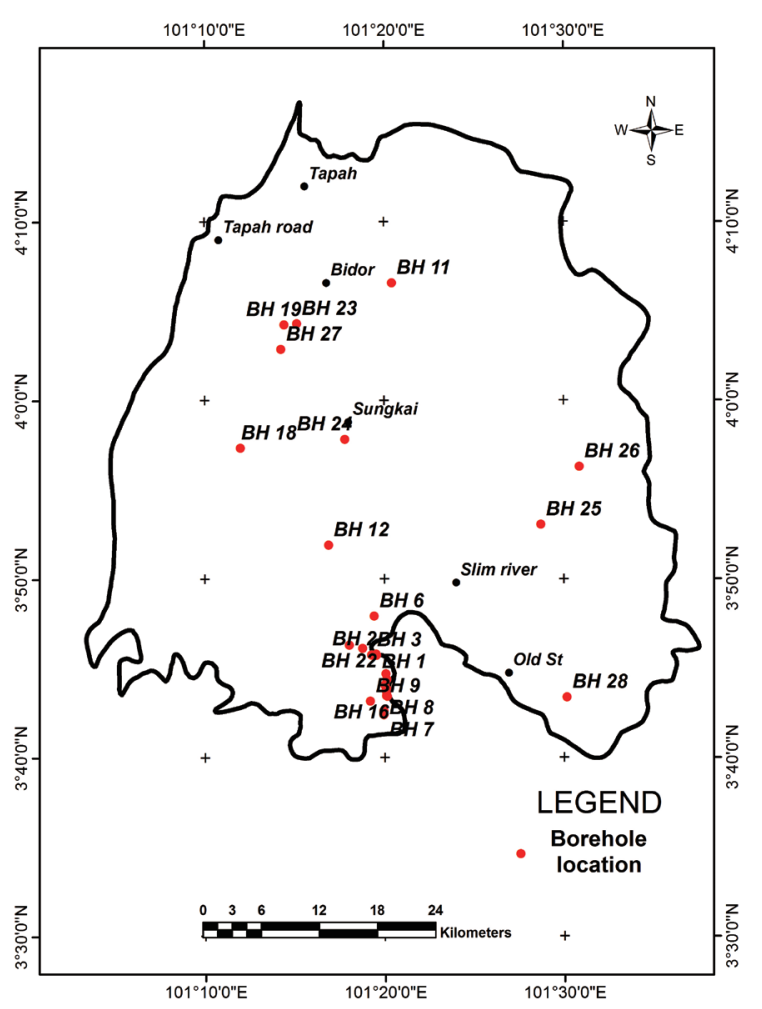

Fig. 3. The borehole distribution inventory map of the area. (Color online only) 
Table 1. Borehole yield records and transmissivity results obtained in the area.

\begin{tabular}{c|ccccc}
\hline BH & LAT & LONG & $\begin{array}{c}\text { Aquifer yield } \\
\left(\mathbf{m}^{3} \mathbf{h}^{-1}\right)\end{array}$ & $\begin{array}{c}\mathbf{B P T}_{\text {Traq }} \\
\left(\mathbf{m}^{2} \mathbf{s}^{-1}\right)\end{array}$ & $\begin{array}{c}\mathbf{B P T}_{\text {Traq }} \\
\left(\mathbf{m}^{2} \mathbf{d a y}\right)\end{array}$ \\
\hline 1 & 416182 & 758308 & 17 & 0.0013 & 112.32 \\
2 & 416304 & 758263 & 18 & 0.0066 & 570.24 \\
3 & 416214 & 757808 & 18.7 & 0.0016 & 138.24 \\
4 & 412613 & 759451 & 14 & 0.0303 & 2617.92 \\
5 & 412612 & 759329 & 14 & 0.0071 & 613.44 \\
6 & 420230 & 758064 & 21 & 0.0036 & 311.04 \\
7 & 410067 & 759080 & 14.7 & 0.001 & 86.4 \\
8 & 410443 & 759079 & 16.29 & 0.0127 & 1097.28 \\
9 & 411468 & 757687 & 10.72 & 0.0013 & 112.32 \\
10 & 411450 & 759032 & 6.9 & 0.0021 & 181.44 \\
11 & 411716 & 759298 & 40 & 0.0017 & 146.88 \\
12 & 411616 & 759198 & 19.63 & 0.0011 & 95.04 \\
13 & 416181 & 757886 & 14.06 & 0.0086 & 743.04 \\
14 & 454638 & 759859 & 2.48 & 0.01 & 864 \\
15 & 410246 & 759591 & 13.86 & 0.0481 & 4155.84 \\
16 & 406952 & 756543 & 14.01 & 0.0002 & 17.28 \\
17 & 424414 & 758753 & 20.4 & 0.0077 & 665.28 \\
18 & 414271 & 759280 & 26.5 & 0.0983 & 8493.12 \\
19 & 413718 & 759574 & 43.71 & 0.1531 & 13227.84 \\
20 & 412513 & 759431 & 18.34 & 0.0109 & 941.76 \\
21 & 411971 & 759431 & 13.97 & 0.0007 & 60.48 \\
22 & 416909 & 756862 & 24.41 & 0.0031 & 267.84 \\
23 & 420497 & 741653 & 20 & 0.009 & 777.6 \\
24 & 414952 & 757311 & 33.7 & 0.0056 & 483.84 \\
25 & 437560 & 744242 & 14.6 & 0.0075 & 648 \\
26 & 413076 & 759094 & 16.6 & 0.0015 & 129.6 \\
27 & 450292 & 748761 & 0.39 & 0.0037 & 319.68 \\
\hline & 413664 & 759150 & 8.67 & 0.0258 & 2229.12 \\
\hline
\end{tabular}

the subsurface is fuzzy in nature where no clear demarcation boundary exists to define the extent of each underlying lithology, as depicted by the inverted 2D imaging sections (Fig. 4). One of the efficient techniques to address this challenge and correctly interpret these $2 \mathrm{D}$ imaging sections is by constraining them with in situ hydrogeological data measurement obtainable from borehole logs. Thus, the lithologs of the available boreholes drilled within the vicinity or on the 2D located points were used as constraints that guided the interpretation of the inverted 2D sections. This condition is achieved by studying and interpreting the borehole lithologs by considering the borehole log description and gamma log lithology description for the mapping of various subsurface layers at varying depths (Fig. 1d). Thereafter, the subsurface parameters, such as layer resistivity and layer thickness, for both overburden materials and aquifer unit were delineated. Since the geology of the study area is largely heterogeneous, the delineated layers (overburden and aquifer) in most cases are multilayered as depicted by the $2 \mathrm{D}$ sections where the resistivity section labeled, Fig. 4a is on location 12 of Fig. 1b, Fig. 4b is on location 19 of Fig. 1b, Fig. 4c is on location 9 of Fig. 1b, Fig. 4d is on location 14 of Fig. 1b, Fig. 4e is on location 11 of Fig. 1b, and Fig. 4f is on location 29 of Fig. 1b. The resistivity of the overburden material and aquifer layers were estimated by first saving the 2D section in XYZ format where " $\mathrm{Z}$ " represents the resistivity parameters at varying depths represented by "Y". Thereafter, the mean of the multilayered resistivity values were estimated with reference to the depth "Y" of the delineated aquifer top. Typical examples of the inverted 2D resistivity imaging sections showing various subsurface strata are presented in Figs. $4 \mathrm{a}$ - $\mathrm{f}$.

\subsubsection{Geoelectrical DZP Modeling}

Bearing in mind the interpreted results from the $2 \mathrm{D}$ resistivity imaging data (Fig. 4) as discussed, two basic geoelectrical parameters such as $\rho$ and $\mathrm{h}$ were determined for the delineated overburden and aquifer layers (Table 2). The DZPs, on the other hand, are the derived variable models based on the geoelectrical parameters using the renowned relevant equations (Maillet 1947). According to Tizro et al. (2010) and Oborie and Udom (2014), the TR and longitudinal conductance $(\mathrm{S})$ are the notable DZPs that are used as a basis to evaluate aquifer properties. The DZP-based mathematical modeling equation for TR for $n$ layers of the delineated subsurface lithologies (Fig. 4) is expressed in the following equation:

$\mathrm{TR}=\sum_{\mathrm{i}=1}^{\mathrm{n}} \rho_{\mathrm{i}} \mathrm{h}_{\mathrm{i}}=\rho_{1} \mathrm{~h}_{1}+\rho_{2} \mathrm{~h}_{2}+\ldots \rho_{\mathrm{n}} \mathrm{h}_{\mathrm{n}}$

Based on Eq. (1), the TR values at each 2D resistivity imaging location were determined. The obtained TR results are presented in column 13 of Table 2 .

\subsection{GIS Tool Application}

\subsubsection{Geospatial Modeling of BPT-Based Transmissivity Record}

Aquifer transmissivity and hydraulic conductivity are the renowned aquifer hydraulic parameters that are often determined through pumping test survey (Ugada et al. 2014). To determine such parameters in this study, the BPT technique principle explore the potential of Cooper and Jacob's straight-line method to analyze the pumping test results of the drawdown reading with respect to time in each drilled borehole in the study area. Each drawdown reading was analyzed at each occupied wells after a specific time interval of pumping. Based on the linear regression technique, the drawdown variables on an arithmetic axis versus time on a logarithmic 
(a)

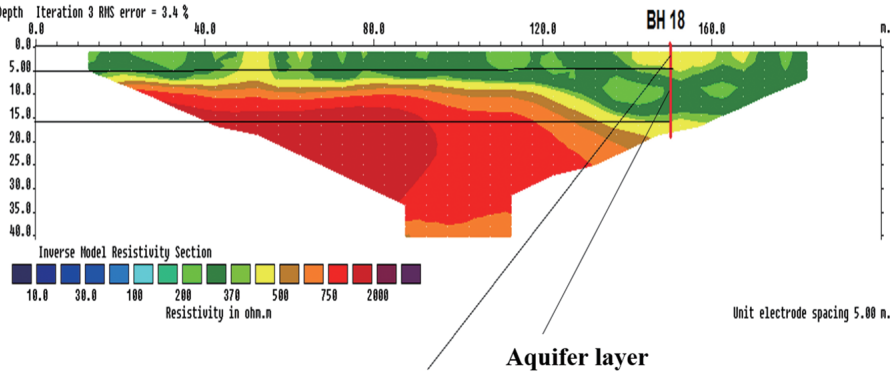

Overburden

material layer

(b)

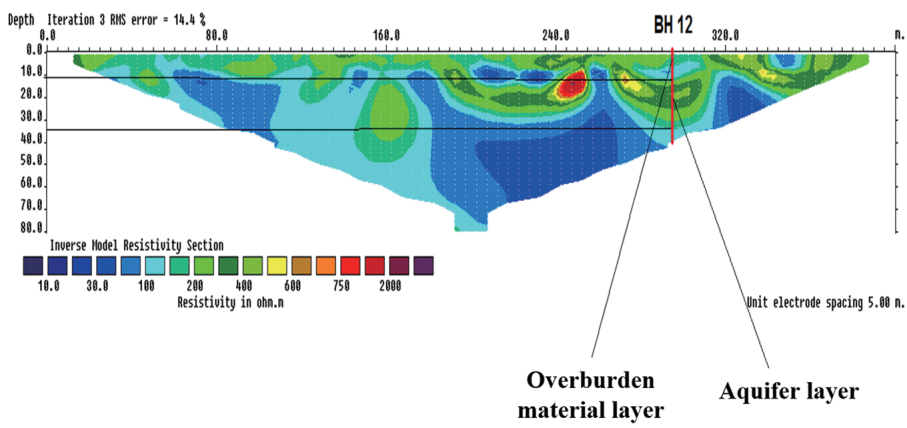

(c)

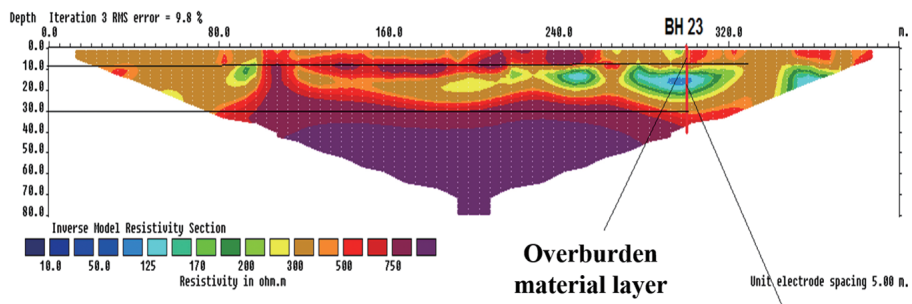

(d)

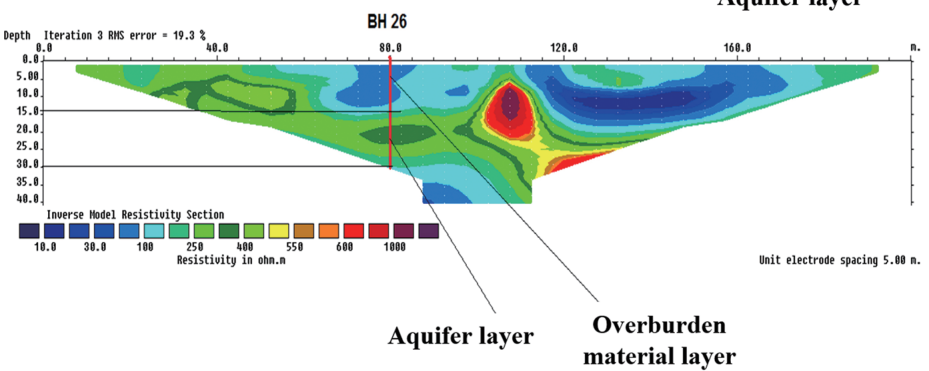

(e) Depth Iteration 3 RHIS error $=9.33_{40.9}$

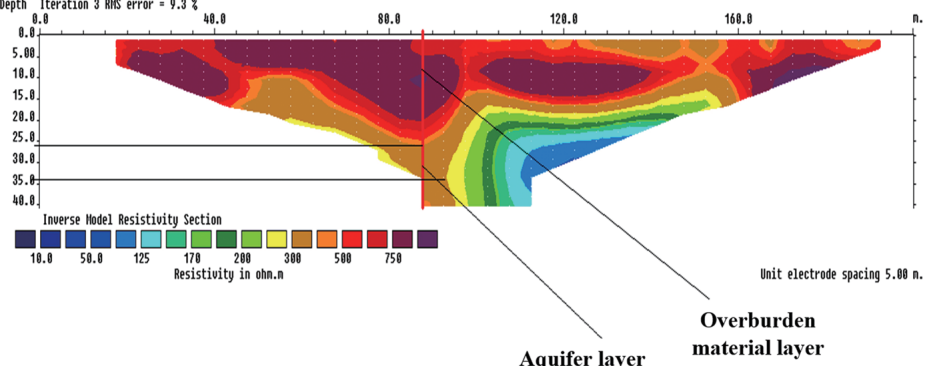

(f) Depth Itteration 3 Ris error $=8.98$

Aquifer layer

160.9

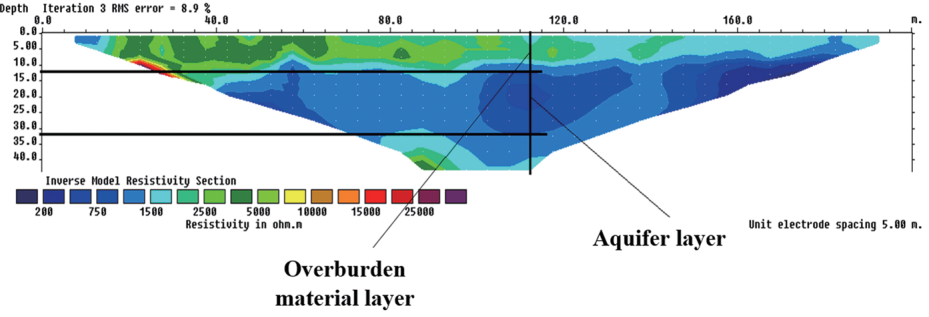

Fig. 4. Examples of the 2D resistivity imaging sections showing how the geoelectrical layers were delineated. (Color online only) 
Table 2. The interpreted geoelectric parameters and the computed hydraulic parameters based on the 2D geophysical data.

\begin{tabular}{|c|c|c|c|c|c|c|c|c|c|c|c|c|}
\hline $\begin{array}{c}2 \mathrm{D} \\
\text { LOC }\end{array}$ & $\mathbf{N}$ & $\mathbf{E}$ & $\begin{array}{c}\mathbf{B P T}_{\text {Traq }} \\
\left(\mathbf{m}^{2} \text { day }^{-1}\right)\end{array}$ & $\begin{array}{c}\text { ACT (h) } \\
\text { (m) }\end{array}$ & $\begin{array}{c}\text { ACR } \\
(\Omega-m)\end{array}$ & $\begin{array}{c}\text { OVT } \\
\text { (m) }\end{array}$ & $\begin{array}{c}\text { OVR } \\
(\Omega-m)\end{array}$ & $\begin{array}{c}\operatorname{Tr} \\
\left(\mathrm{m}^{2} \text { day }^{-1}\right)\end{array}$ & $\begin{array}{l}\mathrm{K}=\mathrm{Tr} / \mathrm{h} \\
\left(\mathrm{m} \text { day }^{-1}\right)\end{array}$ & $S_{t}$ & $\mathbf{D}=\operatorname{Tr} / \mathbf{S}_{\mathrm{t}}$ & $\begin{array}{c}\text { TR } \\
\left(\boldsymbol{\Omega}^{2} \mathbf{m}\right)\end{array}$ \\
\hline 1 & 463204 & 745927 & 691.20 & 13 & 222 & 9 & 94 & 324.40 & 24.95 & 0.000039 & 8318072 & 3732 \\
\hline 2 & 465287 & 754971 & 613.44 & 13 & 464 & 2 & 178 & 746.44 & 57.42 & 0.000039 & 19139569 & 6388 \\
\hline 3 & 467594 & 764259 & 691.20 & 6 & 509 & 3 & 50 & 240.51 & 40.08 & 0.000018 & 13361422 & 3204 \\
\hline 4 & 463747 & 772268 & 794.88 & 14 & 246 & 13 & 126 & 538.92 & 38.49 & 0.000042 & 12831424 & 5082 \\
\hline 5 & 452052 & 749179 & 319.68 & 8 & 241 & 4 & 445 & 295.49 & 36.94 & 0.000024 & 12311875 & 550 \\
\hline 6 & 455548 & 768295 & 552.96 & 6 & 166 & 6 & 979 & 822.56 & 137.09 & 0.000018 & 45697572 & 6867 \\
\hline 7 & 445504 & 736757 & 777.60 & 21 & 600 & 15 & 359 & 1000.21 & 47.63 & 0.000063 & 15876294 & 7985 \\
\hline 8 & 447858 & 748279 & 328.32 & 5 & 75 & 3 & 75 & 144.53 & 28.91 & 0.000015 & 9635333 & 600 \\
\hline 9 & 450071 & 748718 & 267.84 & 3 & 50 & 2.5 & 120 & 120.70 & 40.23 & 0.000009 & 13410556 & 450 \\
\hline 10 & 446769 & 754725 & 518.40 & 5 & 150 & 12 & 480 & 764.24 & 152.85 & 0.000015 & 50949333 & 6500 \\
\hline 11 & 446051 & 762713 & 691.20 & 7 & 150 & 15 & 439 & 944.59 & 134.94 & 0.000021 & 44980548 & 7635 \\
\hline 12 & 437438 & 744320 & 760.32 & 11 & 594 & 15.4 & 219 & 1305.61 & 118.69 & 0.000033 & 39564009 & 9907 \\
\hline 13 & 437156 & 762228 & 1330.56 & 15 & 415 & 15.7 & 363 & 1626.11 & 108.41 & 0.000045 & 36135858 & 11924 \\
\hline 14 & 430581 & 780035 & 950.40 & 16 & 300 & 14 & 201 & 941.25 & 58.83 & 0.000048 & 19609471 & 7614 \\
\hline 15 & 413755 & 772616 & 1339.20 & 10 & 257 & 18 & 355 & 1155.13 & 115.51 & 0.00003 & 38504467 & 8960 \\
\hline 16 & 411097 & 775646 & 1477.44 & 27 & 399 & 15 & 334 & 2239.31 & 82.94 & 0.000081 & 27645786 & 15783 \\
\hline 17 & 411227 & 758588 & 1140.48 & 16 & 170 & 15 & 408 & 1136.07 & 71.00 & 0.000048 & 23668042 & 8840 \\
\hline 18 & 407504 & 756097 & 1036.80 & 8 & 160 & 15 & 312 & 678.43 & 84.80 & 0.000024 & 28268083 & 5960 \\
\hline 19 & 428290 & 752376 & 1183.68 & 22 & 223 & 9 & 222 & 828.44 & 37.66 & 0.000066 & 12552055 & 6904 \\
\hline 20 & 411797 & 747975 & 829.44 & 9 & 227 & 15 & 316 & 809.21 & 89.91 & 0.000027 & 29970693 & 6783 \\
\hline 21 & 417238 & 755739 & 8890.56 & 18 & 181 & 41 & 971 & 6574.58 & 365.25 & 0.000054 & 121751433 & 43066 \\
\hline 22 & 433562 & 737921 & 864.00 & 32 & 331 & 12 & 86 & 1578.44 & 49.33 & 0.000096 & 16442121 & 11624 \\
\hline 23 & 429776 & 734188 & 1183.68 & 8 & 160 & 73 & 106 & 1159.90 & 144.99 & 0.000024 & 48329208 & 8990 \\
\hline 24 & 416459 & 736352 & 1278.72 & 26 & 83 & 20 & 251 & 871.97 & 33.54 & 0.000078 & 11179156 & 7178 \\
\hline 25 & 440713 & 751713 & 725.76 & 11 & 750 & 18 & 242 & 745.81 & 67.80 & 0.000033 & 22600230 & 6384 \\
\hline 26 & 427679 & 759179 & 1149.12 & 15 & 300 & 15.2 & 266 & 1089.99 & 72.67 & 0.000045 & 24221889 & 8550 \\
\hline 27 & 417459 & 786875 & 1287.36 & 17 & 798 & 25 & 562 & 4119.57 & 242.33 & 0.000051 & 80775929 & 27616 \\
\hline 28 & 447635 & 771658 & 285.12 & 5 & 45 & 8 & 34 & 128.64 & 25.73 & 0.000015 & 8576000 & 500 \\
\hline 29 & 450825 & 783823 & 475.20 & 9 & 256 & 5 & 653 & 616.46 & 68.50 & 0.000027 & 22831963 & 5570 \\
\hline 30 & 463794 & 777484 & 293.76 & 3 & 97 & 5.7 & 39 & 130.39 & 43.46 & 0.000009 & 14487544 & 511 \\
\hline
\end{tabular}

Note: ACT: aquifer layer thickness, ACR: aquifer layer resistivity, OVT: overburden layer thickness, $O V R$ : overburden layer resistivity, $B P T_{\text {Traq }}$ : aquifer transmissivity from borehole, Tr: model aquifer transmissivity from $2 D$ geophysical data, K: hydraulic conductivity, St: storativity, D: hydraulic diffusivity, and TR: transverse resistance.

axis were plotted to determine these hydraulic properties when a good correlation coefficient was established as precision guide. Table 1 presents the available records of estimated aquifer transmissivity values based on the BPT approach. Column 6 of the table with the GPS readings observed for each bore well location (columns 2 and 3 ) were processed in the GIS environment to produce BPT aquifer transmissivity map in the area (Fig. 5) by applying geospatial technique on the $\mathrm{BPT}_{\text {Traq }}$ values.

\subsubsection{Geospatial Analysis Between BPT Traq $_{\text {Map and }}$ DZP}

According to Kumar et al. (2001) and Tizro et al. (2010), analytical relations between the aquifer transmissivity and DZPs were developed through geophysical and $\mathrm{BPT}_{\text {Traq }}$ measurements mathematical modeling. This analysis was based on establishing the lithology control influence on the aquifer hydraulic characteristics magnitude. This study established this relationship by applying GIS-based spatial operations. The overlay spatial analysis was conducted between the borehole aquifer transmissivity map (Fig. 5) and the 2D resistivity imaging location point (Fig. 1b) in the GIS environment. The $\mathrm{BPT}_{\text {Traq }}$ values at each $2 \mathrm{D}$ resistivity imaging location point for which TR values were determined were extracted using the "identified tool" in the GIS environment. The extracted $\mathrm{BPT}_{\text {Traq }}$ and corresponding TR values results are presented in Table 2. 


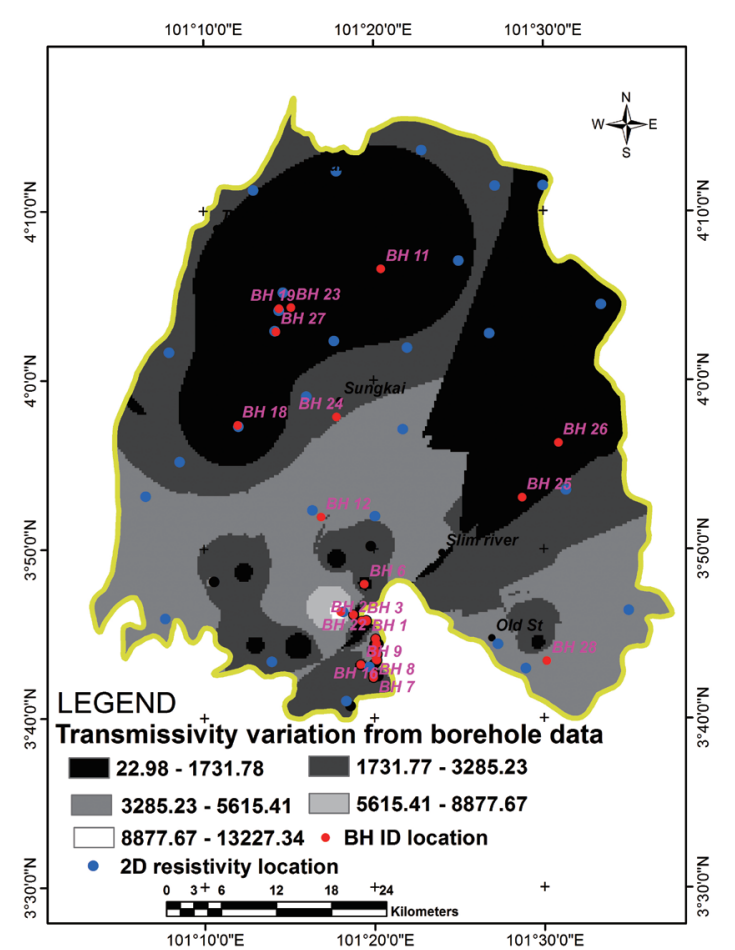

Fig. 5. Spatial map showing the variation of the BPT measured aquifer transmissivity. (Color online only)

\subsection{Linear Regression Technique Application in ATPP Model Equation Development}

\subsubsection{DZP-BPT Measured Aquifer Transmissivity $\left(\mathrm{BPT}_{\text {traq }}\right)$ Relationship}

The regression modeling technique is proficient in examining the relationship between dependent and independent variables. It is a statistical tool used to predict the dependent variable when the independent variable is known. The mathematical model that provides quantitative precision for predictive purposes is developed using this technique. Since some of the objectives of this study are based on using the empirical equation for developing a model, the basic regression model theory is efficiently used. Applying the linear regression technique principle, the obtained $\mathrm{BPT}_{\text {Traq }}$ values in column 4 and the TR values in column 13 of Table 2 were used to generate a linear graph that illustrates the $\mathrm{BPT}_{\text {Traq }}$ value relationship versus the determined TR values, as shown in Fig. 6. The high coefficient of determination value $\left(\mathrm{R}^{2}\right)$ obtained shows that the two variables are well fitted. This $\mathrm{R}^{2}$ value (0.86, which is close to 1 ) further suggests that the estimated TR determined from the geophysical measurement is highly correlated and reliable in predicting or determining the aquifer $\mathrm{Tr}$ even in places where no well is located. With the high regression coefficient line equation of 0.86 as shown in Fig. 6, such model equation is regarded as an ATPP model [Eq. (2)] that can be used to estimate aquifer transmissivity $(\mathrm{Tr}$ ) values at each $2 \mathrm{D}$ location when the TR values are known. This result is in accordance with the findings of Ezeh et al. (2013) and Sattar et al. (2016).

$\mathrm{BPT}_{\text {Traq }}=0.1589(\mathrm{TR})-268.61$

where $\mathrm{BPT}_{\text {Traq }}$ is the predicted aquifer transmissivity, TR (independent variable) is the TR determined from geophysical measurement, -268.61 is the intercept on the y-axis, and the slope is 0.1589. Equation (2) is the proposed ATPP for the study area.

\subsection{Mathematical Modeling of Aquifer Hydraulic Parameters}

The theoretical background behind the aquifer hydraulic parameters according to Nath et al. (2000) has its origin from (1) Darcy's law, (2) water discharge, $\mathrm{Q}\left(\mathrm{m}^{3} \mathrm{~s}^{-1}\right)$, and (3) differential form of Ohm's law. The following equations provide the mathematical expression for the aforementioned origins:

$\mathrm{Q}=\mathrm{KI} A$

$\mathrm{J}=\sigma \mathrm{E}$

where $\mathrm{K}$ = hydraulic conductivity $\left(\mathrm{m}\right.$ day $\left.^{-1}\right), \mathrm{I}^{\prime}=$ hydraulic gradient, $\mathrm{A}=$ area of cross-section perpendicular to the direction of flow, $\mathrm{J}=$ current density $\left(\mathrm{A} \mathrm{m}^{-2}\right), \sigma=$ electrical conductivity (inverse of resistivity in a homogeneous, isotopic medium), and $\mathrm{E}=$ applied electrical field. These two fundamental laws of fluid and current flows may be utilized to find a probable relationship between the electrical and hydraulic characteristics of the formation (Sattar et al. 2016).

Based on the aforementioned theories, the hydraulic properties of any given aquifer system were estimated by applying pumping tests that are conducted on certain borehole sites. However, the paucity of spatial distribution of the available boreholes often results in significant problems in modeling the hydrogeological systems and the drilling of new boreholes often proved to be rather expensive and time consuming. Since the aquifer hydraulic properties estimate according to Soupios et al. (2007) often provides an insight into quantitative information in groundwater flow and contaminant transport modeling, an alternative approach involving surface geophysics measurements was explored (Khan et al. 2002).

From the geophysical point of view, the mathematical method for computing aquifer hydraulic parameters is through the use of DZPs as established by Niwas and Singhal (1981). Such notable aquifer hydraulic parameters, according to Ugada et al. (2014), include Tr, K, $\mathrm{S}_{\mathrm{t}}$, and D. In this study, the aforementioned aquifer hydraulic parameters were 
modeled based on the determined geoelectrical parameters, namely, aquifer layer resistivity ( $\rho$ ), and layer thickness (h), obtained from surface geophysical data measurements interpretation. Based on the proposed ATPP model in Eq. (2), the estimated TR values (determined DZP) at each $2 \mathrm{D}$ resistivity imaging location, as presented in Table 2, were used to compute values for aquifer transmissivity based on the geoelectrical parameters. The modeled aquifer $\mathrm{Tr}$ records are presented in Table 2. Based on the groundwater flow equation [Eq. (5)] adopted by Neshat et al. (2014), the Tr model parameter was substituted to become a modified Eq. (6) as follows:

$\mathrm{T}=\mathrm{K} \times \mathrm{h}$

$\operatorname{Tr}=\mathrm{K} \times \mathrm{h}$

where $\mathrm{K}$ is the hydraulic conductivity of the aquifer $\left(\mathrm{m} \mathrm{day}^{-1}\right)$, $\mathrm{Tr}$ is the aquifer transmissivity $\left(\mathrm{m}^{2}\right.$ day $\left.^{-1}\right)$ based on the geoelectrical parameters, and $\mathrm{h}$ is the aquifer thickness $(\mathrm{m})$ determined from the interpreted $2 \mathrm{D}$ section obtained from the $2 \mathrm{D}$ resistivity imaging data (Table 2 and Fig. 4).

Based on the modified Eq. (6), the hydraulic conductivity $(\mathrm{K})$ value records at each $2 \mathrm{D}$ resistivity location were determined (Table 2).

The following rule of thumb proposed by Lohman (1972) was used to determine the storativity parameter:

$\mathrm{S}_{\mathrm{t}}=3 \times 10^{-6} \mathrm{~h}$

where $S_{t}$ and $h$ are the aquifer storativity and thickness $(\mathrm{m})$ determined from the interpreted 2D section, respectively. The varying values in the estimated $\mathrm{S}_{\mathrm{t}}$ at each $2 \mathrm{D}$ location are presented in Table 2.

The hydraulic diffusivity parameter, on the other hand, was estimated based on the principle established by Hiscock (2005), which stated that the aquifer transmissivity and $S_{t}$ parameter quantities are related to the following equation:

$\mathrm{D}=\frac{\mathrm{Tr}}{\mathrm{S}_{\mathrm{t}}}$

where $\mathrm{D}$ is the hydraulic diffusivity parameter, and both $\operatorname{Tr}$ and $\mathrm{S}_{\mathrm{t}}$ parameter quantities are the estimated records based on the geoelectrical parameter interpreted from the geophysical 2D resistivity sections (Fig. 4).

Thus, Eq. (8) was used to estimate the record values of (D) quantity at each 2D location as presented in Table 2. Equations (2), (6), (7), and (8) are referred to as geoelectrical-based hydraulic parameter (GHP) modeling equations established for the area.

\subsection{APPCF Maps Production}

The underlying aquifer formation potentiality characterizing an area is largely controlled by its physical hydraulic properties. Such hydraulic properties that conditioned the aquifer formation potentiality toward area groundwater resource sustainability include $\mathrm{Tr}, \mathrm{K}, \mathrm{S}_{\mathrm{t}}$, and D (Ugada et al. 2014; Sattar et al. 2016). In this study, these parameters are referred to as APPCFs. This study evaluates the influences of these factors on groundwater occurrences regionally based on GHP modeling equations applicability as discussed in section 3.5. However, to assess the spatial variation of these aquifer hydraulic factor attributes in the investigated area, their maps were produced by processing the computed record values of $\operatorname{Tr}, \mathrm{K}, \mathrm{S}_{\mathrm{t}}$, and D (Table 2) in the GIS environment as shown in Fig. 7. Furthermore, to adequately synthesize the map of these factors that have varying degrees of contribution to aquifer potentiality productivity and are largely space-dependent, the AHP-MCDA principle is applied in the map modeling (Fig. 7). But then, for effective decision making when exploring the potential of the multicriteria integrating application of the AHP-MCDA model, knowledge of the APPCFs' hydrological significance in groundwater potential mapping in the area is essential.

\subsubsection{Assessment of APPCFs Hydrological Significance}

With reference to section 3.6, four APPCFs considered for evaluating groundwater potential include $\mathrm{Tr}, \mathrm{K}, \mathrm{S}_{\mathrm{t}}$, and D. Studies have established that the optimization and effective management of the hydrogeological potential of an area depends largely on these aquifer hydraulic parameters. Furthermore, in view of the holistic appraisement of bore well productivity in terms of its quality status safeguarding and safe discharge of groundwater, knowledge of these aquifer formation's properties in an area is very essential (Soupios et al. 2007; Ugada et al. 2014; Sattar et al. 2016). In assessing the hydrological significance of these factors in the area, their varying hydraulic properties, which determine the natural flow of water through an aquifer and its response to fluid extraction in the area, guide the assignment of weights to each factor such that the relative importance of the factor to groundwater accumulation is reflected. Consequently, the Tr parameter was considered as the most significant parameter because the investigated area is underlain with aquifer formation with relative thick overburden as reflected in the higher TR values characterizing the area. Accordingly, for $\operatorname{Tr}$ and TR, a direct relation established in the area implies good groundwater potential (Adiat et al. 2013). The hydraulic conductivity parameter, on the other hand, is considered as the next rated factor because the observed resistivity properties of the delineated aquifer formation in the area highly suggested a saturated formation (97 - $600 \Omega \mathrm{m}$, column 6 of Table 2), which indicates good groundwater potential in the 


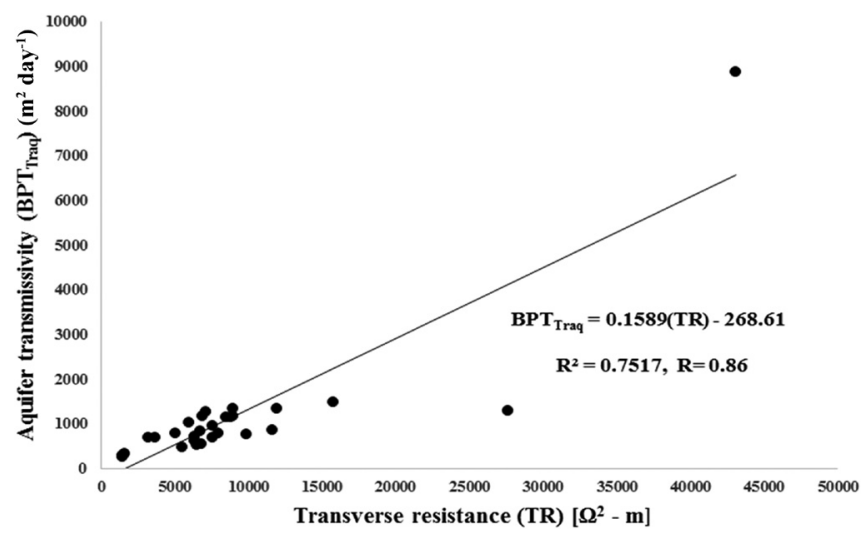

Fig. 6. Linear relation between the BPT aquifer transmissivity and the estimated TR values.
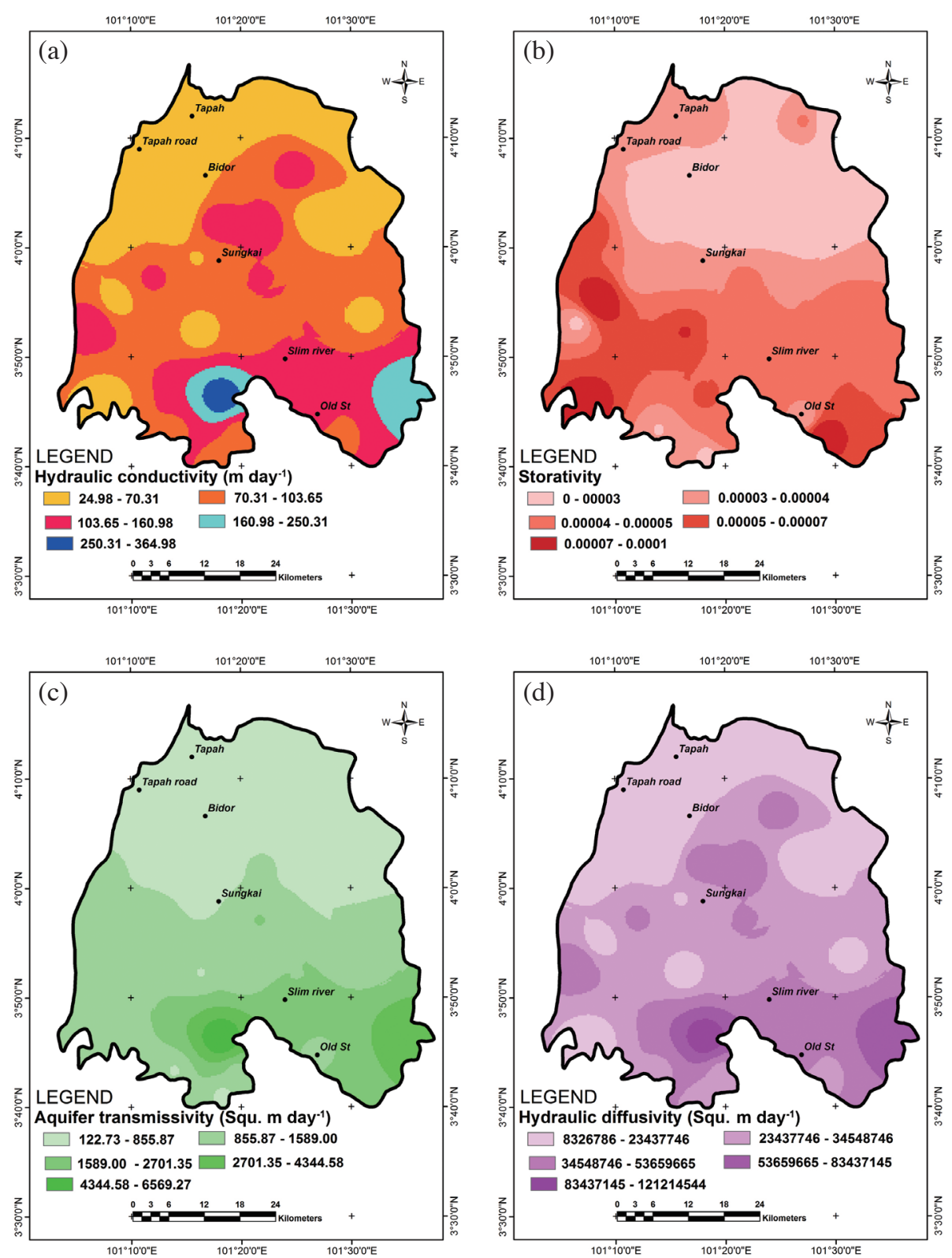

Fig. 7. The derived hydraulic parameters thematic maps based on geoelectric measurements used in AHP modeling approach, (a) hydraulic conductivity; (b) storativity; (c) transmissivity; and (d) hydraulic diffusivity. (Color online only) 
area. Similarly, the other hydraulic property factors were assigned weights according to their relative importance to groundwater occurrences in the area.

\subsection{AHP-MCDA Method and its Applicability in Groundwater Potential Mapping}

The MCDA is a general field of knowledge driven technique that entails decision making in the presence of two or more conflicting objectives. It is also a process for analyzing decisions when two or more attributes are involved (Tecle and Duckstein 1994). Its role in formalizing and addressing the problems of competing decision objectives make it an important tool in environmental decision making (Janssen 1992; Lahdelma et al. 2000; Linkov et al. 2006; Regan et al. 2007). Among the various MCDA systems, the AHP technique is the most commonly used (Awasthi and Chauhan 2011). AHP is a powerful and flexible process where decision making is weighed to help people set priorities and make the best decision (Ariff et al. 2008). Generally, the AHP implementation is based on expert experience and knowledge to determine the factors or criteria that influence the decision-making process (Ho 2008; Dweiri and Al-Oqla 2006). AHP can effectively handle both subjective and objective evaluation measures. Moreover, AHP provides a useful technique for checking the consistency of evaluation measures and alternatives proposed by experts or decision makers. The bias that is likely present in the decision-making process is consequently reduced (Ariff et al. 2008). Owing to the uniqueness of the AHP technique, its potential was widely explored in groundwater hydrology with satisfactory results in a number of case histories (Thirumalaivasan et al. 2003; Adiat et al. 2012; Zhou and Chen 2014; Mogaji et al. 2014) with entreaty results. Thus, this study employed the AHP technique in groundwater potential mapping. The AHP was used to determine the weights of the four APPCFs by constructing a pairwise comparison matrix. The pairwise comparison process, based on a standard Saaty scale of 1 - 9 (Table 3), entails considering two factors $(\operatorname{Tr} / \mathrm{K})$ at a time, with each factor being scored according to its relative influence on the area groundwater occurrence. This condition results in a ratio of importance for each pair with the maximum difference of having one factor that is nine times more important than the other (Table 3). Based on expert opinions obtained from previous reports coupled with intuitive knowledge of the researchers on the APPCF characteristics in the area (discussed in section 3.6.1), the Saaty scale standard and the Kardi (2006) technique as used by Adiat et al. (2013), the pair-wise comparison matrix for the selected aquifer hydraulic parameters shown in Table 3 was developed. Table 3 was solved to determine the aquifer hydraulic parameter weights by computing the sum of the value in each column in the table, using the total number of columns to divide each element in the matrix to produce the normalized matrix in Table 4 . The estimate of the averages of the elements in each row in Table 4 provides the relative weights of the aquifer hydraulic parameters being compared. Since the comparison of the APPCFs was conducted through personal or subjective judgments, a certain level of inconsistency and bias may occur. To guarantee some levels of consistency in the judgments, consistency verification was conducted to check the logical consistency of the pairwise matrix based on the following procedures:

(1) The weighted sum vector was estimated by multiplying the weights from the first factor (transmissivity) in Table 4 multiplied by the first column of the original pairwise comparison matrix (Table 3). The weight from the second factor (hydraulic conductivity) was then multiplied by the second column until the last factor (hydraulic diffusivity) to produce Table 5 .

(2) The consistency vector (column 5) is computed by dividing the weighted sum vector (column 3 ) by the factor weights (column 4) of Table 5.

With the output of computed consistency vector (Table 5), the mathematical formulas for Eqs. (9) and (10), as adopted by Zhou and Chen (2014), were used to estimate the consistency ratio as 0.07356 based on the following equation:

$\mathrm{CI}=\frac{\lambda_{\max }-\mathrm{n}}{\mathrm{n}-1}$

where $\mathrm{CI}$ is the consistency index, $\lambda_{\max }$ is the average value of the consistency vector in column 5 of Table 5 , and $n=$ number of factors (i.e., 4).

From Table 5, $\lambda_{\max }=16.79 / 4=4.20$.

Based on Eq. (9), CI $=4.20-4 / 4-1=0.067$ through

$\mathrm{CR}=\frac{\mathrm{CI}}{\mathrm{RI}}$

where $\mathrm{CR}$ is the consistency ratio and RI is the random index whose value depends on the number ( $n$ ) of factors being compared.

For $\mathrm{n}=4, \mathrm{RI}=0.90$ (Saaty 1980).

Based on Eq. (10), CR =0.067/0.9=0.07356.

Based on $0.074<0.1$, the obtained CR implies that the pair-wise comparison has a reasonable level of consistency supported by Feizizadeh et al. (2014). Thus, the constructed matrix (Table 3 ) is consistent and the weights $0.49,0.29$, 0.15 , and 0.07 are assigned to aquifers $\operatorname{Tr}, \mathrm{K}, \mathrm{S}_{\mathrm{t}}$, and $\mathrm{D}$, respectively (see column 5 of Table 6 ).

\subsection{Development of APMI Model}

To multi-critically synthesize the produced APPCF 
thematic maps as inputs for the groundwater potential mapping in the investigated area, an index model referred to as APMI that performs multi criteria integration was developed. The weighted linear average (WLA) technique was applied to develop the APMI model in this study. The WLA approach technique is usually specified in terms of normalized weights for each factor as well as normalized scores for all options relative to each criterion (Adiat et al. 2012). Based on the WLA technique, the expected output $U$ for each option $\mathrm{Oi}$ is expressed as follows:

$$
\mathrm{U}(\mathrm{Oi})=\sum_{\mathrm{R}=\mathrm{i}}^{\mathrm{R}=\mathrm{n}} \mathrm{Z}_{\mathrm{R}}(\mathrm{Oi}) \times \mathrm{W}\left(\mathrm{C}_{\mathrm{R}}\right)
$$

where $\mathrm{Z}_{\mathrm{R}}(\mathrm{Oi})$ is the normalized score of option Oi under criterion $C_{R}$ and $W\left(C_{R}\right)$ is the normalized weighting for each APPCF. When the left hand side (LHS) of Eq. (11) is replaced with APMI and the right hand side (RHS) with the sum of the products of the normalized weights (W) and ratings (R) for each factor, the APMI model shown in the following equation is developed in accordance with the work of Jha et al. (2010) and Adiat et al. (2012):

$$
\mathrm{APMI}=\operatorname{Tr}_{\mathrm{W}} \operatorname{Tr}_{\mathrm{R}}+\mathrm{K}_{\mathrm{W}} \mathrm{K}_{\mathrm{R}}+\mathrm{S}_{\mathrm{W}} \mathrm{S}_{\mathrm{R}}+\mathrm{D}_{\mathrm{W}} \mathrm{D}_{\mathrm{R}}
$$

where the subscripts $\mathrm{W}$ and $\mathrm{R}$ are the normalized weights and ratings for each hydraulic parameter, respectively.

\section{RESULTS AND DISCUSSION}

\subsection{Application Results of GHP Parameter Modeling Equations}

The conceptual modeling to determine the aquifer hydraulic parameters from the viewpoint of geophysical measurement was called the GHP parameter modeling equations in this study. Consequently, the GHP modeling equations

\begin{tabular}{|c|c|c|c|c|c|c|c|c|}
\hline \multicolumn{9}{|c|}{ Pairwise comparison 9 point continuous rating scale } \\
\hline \multicolumn{4}{|c|}{ Less important } & & \multicolumn{4}{|c|}{ More important } \\
\hline $1 / 9$ & $1 / 7$ & $1 / 5$ & $1 / 3$ & 1 & 3 & 5 & 7 & 9 \\
\hline \multirow[t]{2}{*}{ Extremely } & Very strongly & strongly & Moderately & Equally & Moderately & Strongly & Very strongly & Extremely \\
\hline & & & Tr & $\mathbf{K}$ & $\mathbf{S}_{\mathrm{t}}$ & $\mathbf{D}$ & & \\
\hline $\operatorname{Tr}$ & & & 1 & 3 & 3 & 5 & & \\
\hline $\mathbf{K}$ & & & $1 / 3$ & 1 & 3 & 5 & & \\
\hline $\mathbf{S}_{\mathrm{t}}$ & & & $1 / 3$ & $1 / 3$ & 1 & 3 & & \\
\hline D & & & $1 / 5$ & $1 / 5$ & $1 / 3$ & 1 & & \\
\hline Column Total & & & 1.8667 & 4.533 & 7.333 & 14 & & \\
\hline
\end{tabular}

Table 3. Matrix of pair-wise comparisons of APPCFs for the AHP process.

Table 4. Determining the relative APPCFs weights.

\begin{tabular}{c|ccccc}
\hline & $\boldsymbol{W}_{\boldsymbol{k} j}(\mathbf{j}=\mathbf{1})$ & $\boldsymbol{W}_{k j}(\mathbf{j}=\mathbf{2})$ & $\boldsymbol{W}_{\boldsymbol{k j}}(\mathbf{j}=\mathbf{3})$ & $\boldsymbol{W}_{\boldsymbol{k} j}(\mathbf{j}=\mathbf{4})$ & Weights $=\frac{\mathbf{1}}{\boldsymbol{n}} \sum \boldsymbol{W}_{k j}$ \\
\hline $\operatorname{Tr}(\mathrm{K}=1)$ & 0.535 & 0.661 & 0.409 & 0.357 & 0.49 \\
$\mathrm{~K}(\mathrm{~K}=2)$ & 0.178 & 0.221 & 0.409 & 0.357 & 0.29 \\
$\mathrm{~S}_{\mathrm{t}}(\mathrm{K}=3)$ & 0.178 & 0.073 & 0.136 & 0.214 & 0.15 \\
$\mathrm{D}(\mathrm{K}=4)$ & 0.107 & 0.044 & 0.045 & 0.071 & 0.07 \\
$\Sigma$ Column & 1 & 1 & 1 & 1 & 1 \\
\hline
\end{tabular}

Table 5. Computation of the consistency vector.

\begin{tabular}{c|c|ccc}
\hline \multicolumn{2}{c|}{} & Weighted Sum $(\boldsymbol{\Sigma W S})$ & Relative weight $(\mathbf{W})$ & Consistency vector \\
\hline $\mathrm{Tr}$ & $1(0.49)+3(0.29)+3(0.15)+5(0.07)=2.15$ & 2.15 & 0.49 & $2.15 / 0.49=4.38$ \\
$\mathrm{~K}$ & $1 / 3(0.49)+1(0.29)+3(0.15)+5(0.07)=1.24$ & 1.24 & 0.29 & $1.24 / 0.29=4.26$ \\
$\mathrm{~S}_{\mathrm{t}}$ & $1 / 3(0.49)+1 / 3(0.29)+1(0.15)+3(0.07)=0.61$ & 0.61 & 0.15 & $0.61 / 0.15=4.06$ \\
$\mathrm{D}$ & $1 / 5(0.49)+1 / 5(0.29)+1 / 3(0.15)+1(0.07)=0.27$ & 0.27 & 0.07 & $0.27 / 0.07=4.09$ \\
\hline
\end{tabular}


Table 6. Probability weighted and rating (R) for the classes of APPCFs maps.

\begin{tabular}{|c|c|c|c|c|}
\hline The APPCFs maps & Category (classes) & Aquifer expected Productivity potentiality & Rating (R) & Normalized Weight (w) \\
\hline \multirow{5}{*}{ Aquifer transmissivity $(\mathrm{Tr})$} & $122.73-855.87$ & Very low & 1 & \multirow{5}{*}{0.49} \\
\hline & $855.87-1589.00$ & Low & 2 & \\
\hline & $1589.00-2701.35$ & Medium & 3 & \\
\hline & $2701.35-4344.58$ & Medium - High & 4 & \\
\hline & $4344.58-6569.27$ & High & 5 & \\
\hline \multirow{5}{*}{ Storativity $\left(\mathrm{S}_{\mathrm{t}}\right)$} & $0.00000-0.00003$ & Very low & 1 & \multirow{5}{*}{0.15} \\
\hline & $0.00003-0.00004$ & Low & 2 & \\
\hline & $0.00004-0.00005$ & Medium & 3 & \\
\hline & $0.00005-0.00007$ & Medium - High & 4 & \\
\hline & $0.00007-0.0001$ & High & 5 & \\
\hline \multirow{5}{*}{ Hydraulic conductivity $(\mathrm{K})$} & $24.98-70.31$ & Very low & 1 & \multirow{5}{*}{0.29} \\
\hline & $70.31-103.65$ & Low & 2 & \\
\hline & $103.65-160.98$ & Medium & 3 & \\
\hline & $160.98-250.31$ & Medium - High & 4 & \\
\hline & $250.31-364.98$ & High & 5 & \\
\hline \multirow{5}{*}{ Hydraulic diffusivity (D) } & 8326786 - 23437746 & Very low & 1 & \multirow{5}{*}{0.07} \\
\hline & $23437746-34548746$ & Low & 2 & \\
\hline & $34548746-53659665$ & Medium & 3 & \\
\hline & $53659665-83437145$ & Medium - High & 4 & \\
\hline & $83437145-121214544$ & High & 5 & \\
\hline
\end{tabular}

were derived for $\operatorname{Tr}, \mathrm{K}, \mathrm{S}_{\mathrm{t}}$, and $\mathrm{D}$. The application results of the GHP modeling equation of each parameter at each 2D location (Fig. 1b) are presented in Table 2. Through the GIS technique, the results of the computed $\operatorname{Tr}, \mathrm{K}, \mathrm{S}_{\mathrm{t}}$, and $\mathrm{D}$ in Table 2 were processed to produce the thematic maps shown in Fig. 7. The area aquifer transmissivity, according to Kaliraj et al. (2014), is the groundwater discharge from a unit of area within a unit of time and is measured in square meters per day. When the GHP modeling is applied in Eq. (2), the $\mathrm{Tr}$ values in the range of $120.7-6574.27 \mathrm{~m}^{2}$ day $^{-1}$ for the area were estimated by substituting the TR values in column 13 of Table 2. Figure 7a presents the Tr thematic map that depicts the spatial variation in aquifer transmissivity values in the area. The super imposition correlation of the Tr map with the geologic map (Fig. 1c) revealed that the $\operatorname{Tr}$ properties in the area are largely controlled by the underlying rock type. Quantitatively, the minimum and maximum values of $\operatorname{Tr}$ that characterizes the QUA, DEV, SIL, and ING based on the occupied 2D location are in the range of 871.97 - 1578.44, 809.21 - 6574.74, 120.7 - 2239.31, and $128.64-4119.57 \mathrm{~m}^{2}$ day $^{-1}$, respectively. The computed mean $\operatorname{Tr}$ values across these rock units are 1175.37, 2009.61, 836.09, and $942.29 \mathrm{~m}^{2}$ day $^{-1}$, respectively. The geology influence on the area underlain aquifer potential productivity is qualitatively established from the varying $\operatorname{Tr}$ values based on the mean analyzed results. Cardinally, the relative zones of low transmissivity values identified in the northern part of the area are relatively poor for groundwater prospect, whereas the southern part of the area has relatively higher transmissivity values, thereby implying the presence of good aquifer materials in this part of the area. Thus, the southern part of the area is inferred as good groundwater prospect zones. Corroboratively, the productive borehole concentration in the southern area confirms this finding (see Fig. 3). The hydraulic conductivity property denoted by $\mathrm{K}$, on the other hand, refers to the ability of a rock material to conduct fluids under a hydraulic gradient unit (Sattar et al. 2016). In this study, $\mathrm{K}$ that was estimated by applying GHP modeling Eq. (6) provides the values at each 2D location (see column 10 of Table 2). The processed $\mathrm{K}$ values in the GIS environment produced a $\mathrm{K}$ thematic map (Fig. 7b). Through deduction from the spatial analysis of the $\mathrm{K}$ thematic map with the geology map (Fig. 1c) and Table 2, the minimum $\mathrm{K}$ values of about $24.95 \mathrm{~m}_{\text {day }}{ }^{-1}$ at $2 \mathrm{D}$ location 1 is identified on SIL geology. The clayey material composition of this rock unit's aquifer formation as revealed from the interpreted borehole lithologs (Fig. 1d) is responsible for the low $\mathrm{K}$ values. Meanwhile, the observed maximum $\mathrm{K}$ values $\left(365.25 \mathrm{~m} \mathrm{day}^{-1}\right)$ are associated with 2D location 21 within the DEV geology. The aquifer formation material composition interpreted from the litholog in the DEV geology has more sand than clay and thus has higher porosity, which contributes to the high $\mathrm{K}$ value. The areas of maximum $\mathrm{K}$ values (Fig. 7b) also coincided with 
the areas of maximum Tr values (Fig. 7a). Such identified zones of relatively low $\mathrm{K}$ values that mostly concentrated in the northern area included very few patches across the area have poor groundwater prospects, whereas the southern portion of the area was notable for good groundwater potential prospects because of high $\mathrm{K}$ value characteristics. The $\mathrm{S}_{\mathrm{t}}$ property of the aquifer formation defines its capability to store and release water. With the application of GHP modeling in Eq. (7) at each occupied 2D location, the degrees/ values of $S_{t}$ variation in the range of $9 \times 10^{-6}-9.6 \times 10^{-6}$ for the study area was evaluated (see column 11 of Table 2). The geospatial modeling of the computed $S_{t}$ values produced the $S_{t}$ thematic map (Fig. 7c). The zones of low $S_{t}$ values identified around the 2D location (9) also on the SIL geology are observed and correlated to areas of low $\mathrm{Tr}$ values in the northern part. However, the underlying aquifer formations in the southwestern and southeastern parts of the area are characterized by high storage coefficient properties. Thus, feasible decision making for successful groundwater potential mapping in the area is guided by these analyzed $S_{t}$ results. Furthermore, the aquifer formation property that determines its quick response to fluid transmissivity is the aquifer hydraulic diffusivity parameter denoted by D (Hiscock 2005). The degree of parameter D in an area is largely influenced by the aquifer formation hydraulic conditions that often change from one area to another. When the established GHP modeling in Eq. (8) is applied, the varying values of $\mathrm{D}$ were estimated at each occupied 2D location where parameters $\operatorname{Tr}$ and $\mathrm{S}_{\mathrm{t}}$ are known. The estimated D values vary from $8.32 \times 10^{6}-1.22 \times 10^{8} \mathrm{~m}^{2}$ day $^{-1}$. The processed D values (column 12, Table 2 ) in the GIS environment produced the D thematic map (Fig. 7d). Similarly, the northern part of the area is characterized with low $\mathrm{D}$ values relative to the southern part. The qualitative interpretation results based on surface geologic rock units and available bore well lithologs (Figs. 1c and d) agree with the analyzed aquifer formation hydraulic diffusivity characteristics in the area. Thus, the zones in the study area that have large D values typify good aquifer formation hydraulic conditions that can be explored for successful groundwater productivity mapping.

\subsection{APMI Estimation}

The hydrogeological relevance of the considered APP$\mathrm{CFs}$ in groundwater potential mapping in the area was qualitatively and quantitatively evaluated in section 4.1. The APPCF thematic maps (Fig. 7) were then used as inputs to estimate APMI values/scores in the area. Thus, the developed numerical model in Eq. (12) established the relationship between the four produced aquifer hydraulic parameter factors and the APMI employed in the quantitative evaluation of the groundwater reservoir potential in the area. However, to apply Eq. (12), the generated APPCF thematic maps (Fig. 7) were rated R on a scale factor of 1 - 5 in column 4 of Table 6 according to Saud (2010), with consideration that the class boundary of each map influences the aquifer potential in the area. In implementing the rating scale, based on the grid coverage pixel values in a raster map, the produced APPCF thematic maps were gridded to 36 centered locations using the grid size of $6 \mathrm{~km}^{2}$ with fishnet module algorithm application in the GIS environment. Figure 8 presents the template model for raster gridding. Using the template model in Fig. 8, the rating (R) scale of 1 - 5 was assigned at each grid center across all the APPCF thematic maps according to the interpretation influence of the class boundaries of each map on the aquifer-expected productivity potentiality (column 3 , Table 6). The assigned rating (R) and normalized weights (W) determined for the APPCF thematic maps in column 5 of Table 6 estimated with the AHP technique were used in Eq. (12) to obtain APMI estimated values for all the grids as presented in column 12 of Table 7.

\subsubsection{Development of GRPPM Map}

To produce the output surface map of the area groundwater reservoir (aquifer) productivity potential model, the GIS-based geostatistical interpolation technique was applied. The APMI values estimated for each grid center location were noted to be a series of continuous values in the range of $0.2246-4.4897$ (column 12, Table 7), were processed by employing the kriging interpolation technique

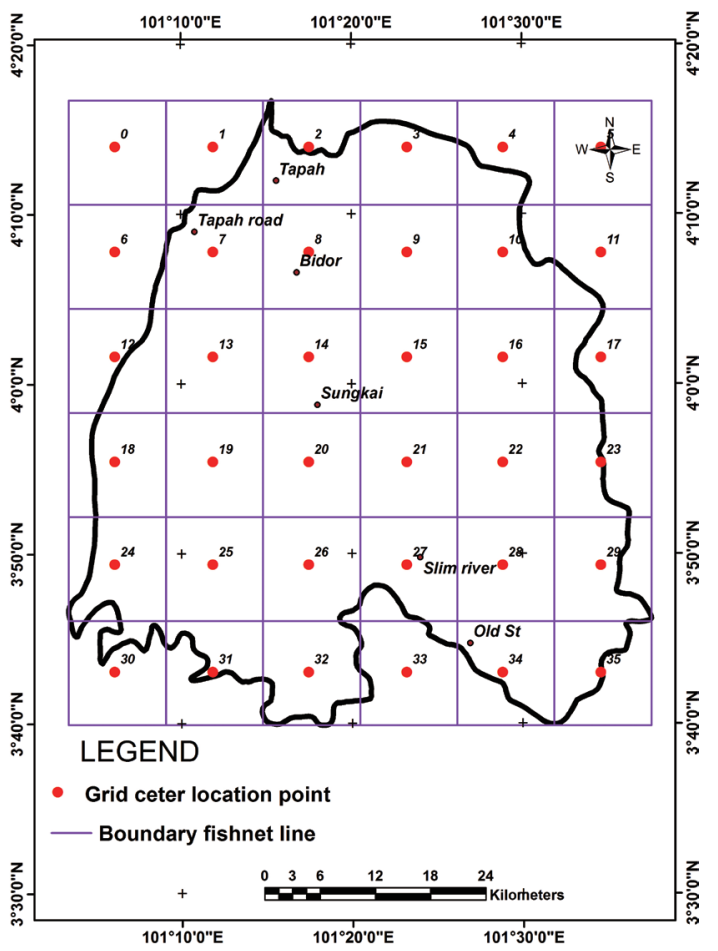

Fig. 8 Raster grid creating templated model used for the AHP-MCDA model approach. (Color online only) 
Table 7. Aquifer potential mapping index (APMI) estimation.

\begin{tabular}{|c|c|c|c|c|c|c|c|c|c|c|c|}
\hline Grid & Grid Cent & coordinate & $\operatorname{Tr}$ & $V=0.49)$ & & $=0.15)$ & & $=0.29)$ & D ( & $=0.07)$ & DMI NW*D \\
\hline No & Easting & Northing & $\mathbf{R}$ & $\mathbf{W} \times \mathbf{R}$ & $\mathbf{R}$ & $\mathbf{W} \times \mathbf{R}$ & $\mathbf{R}$ & $\mathbf{W} \times \mathbf{R}$ & $\mathbf{R}$ & $\mathbf{W} \times \mathbf{R}$ & AThinger \\
\hline 1 & 754386 & 468233 & 2 & 0.98 & 2 & 0.3 & 2 & 0.58 & 3 & 0.21 & 2.07 \\
\hline 2 & 765043 & 468233 & 2 & 0.98 & 1 & 0.15 & 1 & 0.29 & 2 & 0.14 & 1.56 \\
\hline 3 & 743978 & 456834 & 2 & 0.98 & 1 & 0.15 & 1 & 0.29 & 2 & 0.14 & 1.56 \\
\hline 4 & 754386 & 456834 & 2 & 0.98 & 1 & 0.15 & 1 & 0.29 & 2 & 0.14 & 1.56 \\
\hline 5 & 765043 & 456834 & 2 & 0.98 & 1 & 0.15 & 3 & 0.87 & 3 & 0.21 & 2.21 \\
\hline 6 & 775451 & 456834 & 2 & 0.98 & 1 & 0.15 & 2 & 0.58 & 3 & 0.21 & 1.92 \\
\hline 7 & 733322 & 445434 & 3 & 1.47 & 4 & 0.6 & 1 & 0.29 & 2 & 0.14 & 2.5 \\
\hline 8 & 743978 & 445434 & 1 & 0.49 & 2 & 0.3 & 1 & 0.29 & 2 & 0.14 & 1.22 \\
\hline 9 & 754386 & 445434 & 1 & 0.49 & 1 & 0.15 & 5 & 1.45 & 5 & 0.35 & 2.44 \\
\hline 10 & 765043 & 445434 & 3 & 1.47 & 1 & 0.15 & 3 & 0.87 & 4 & 0.28 & 2.77 \\
\hline 11 & 775451 & 445434 & 1 & 0.49 & 1 & 0.15 & 1 & 0.29 & 1 & 0.07 & 1 \\
\hline 12 & 733322 & 434035 & 3 & 1.47 & 4 & 0.6 & 3 & 0.87 & 4 & 0.28 & 3.22 \\
\hline 13 & 743978 & 434035 & 3 & 1.47 & 3 & 0.45 & 3 & 0.87 & 4 & 0.28 & 3.07 \\
\hline 14 & 754386 & 434035 & 3 & 1.47 & 3 & 0.45 & 2 & 0.58 & 2 & 0.14 & 2.64 \\
\hline 15 & 765043 & 434035 & 3 & 1.47 & 3 & 0.45 & 3 & 0.87 & 3 & 0.21 & 3 \\
\hline 16 & 775451 & 434035 & 3 & 1.47 & 3 & 0.45 & 2 & 0.58 & 2 & 0.14 & 2.64 \\
\hline 17 & 786107 & 434035 & 3 & 1.47 & 3 & 0.45 & 2 & 0.58 & 2 & 0.14 & 2.64 \\
\hline 18 & 733322 & 422883 & 3 & 1.47 & 4 & 0.6 & 3 & 0.87 & 2 & 0.14 & 3.08 \\
\hline 19 & 743978 & 422883 & 3 & 1.47 & 4 & 0.6 & 3 & 0.87 & 3 & 0.21 & 3.15 \\
\hline 20 & 754386 & 422883 & 4 & 1.96 & 4 & 0.6 & 4 & 1.16 & 4 & 0.28 & 4 \\
\hline 21 & 765043 & 422883 & 4 & 1.96 & 3 & 0.45 & 3 & 0.87 & 3 & 0.21 & 3.49 \\
\hline 22 & 775451 & 422883 & 4 & 1.96 & 3 & 0.45 & 3 & 0.87 & 3 & 0.21 & 3.49 \\
\hline 23 & 786107 & 422883 & 5 & 2.45 & 3 & 0.45 & 4 & 1.16 & 4 & 0.28 & 4.34 \\
\hline 24 & 743978 & 411235 & 3 & 1.47 & 2 & 0.3 & 3 & 0.87 & 3 & 0.21 & 2.85 \\
\hline 25 & 754386 & 411235 & 4 & 1.96 & 2 & 0.3 & 3 & 0.87 & 3 & 0.21 & 3.34 \\
\hline 26 & 775451 & 411235 & 4 & 1.96 & 5 & 0.75 & 2 & 0.58 & 2 & 0.14 & 3.43 \\
\hline 27 & 786107 & 411235 & 5 & 2.45 & 4 & 0.6 & 4 & 1.16 & 4 & 0.28 & 4.49 \\
\hline
\end{tabular}

with application of the natural break classification method according to He et al. (2011) to demarcate the potential zones of the area into varying classes (Table 8). According to the classification analysis in Table 8, the GRPPM map was produced for the study area (Fig. 9). However, to ensure that the produced groundwater reservoir productivity potential index model provides accurate predictions of the study area, the geostatistical analysis was conducted by performing cross-validation on the predicted model map. From the prediction analyzed results, the obtained mean prediction error (ME) values (0.062) for the GRPPM map was close to zero, which implies an unbiased prediction. The RMS standardized value (1.05) tends to be 1 , thereby demonstrating the accuracy and precision of the GRPPM map. In addition, a small RMSE value (0.97) indicates similarity between the predicted and measured values. Furthermore, the corresponding areal coverage and percentage in each category of predicted aquifer productivity potential zones were evaluat- ed, where approximately $737.79 \mathrm{~km}^{2}(26 \%)$ and $571.52 \mathrm{~km}^{2}$ $(20 \%)$ account for the low and low-medium categories. Both the medium and medium-high categories have an area coverage of $1074.11 \mathrm{~km}^{2}(38 \%)$ and $464.38 \mathrm{~km}^{2}(16 \%)$, respectively (Table 8 ). Based on the areal coverage extent analysis, more than half (54\%) of the area, particularly in the southern region, are highly recommended because of their good groundwater potential.

\subsection{Model Validations}

Validations were conducted in this study on the two developed predictive models, namely, the linear aquifer hydraulic parameter predictive model and the accuracy validation of the produced GRPPM map. The proposed ATPP model in Eq. (2) is characterized by an $\mathrm{R}^{2}$ value of 0.7517 . The high $\mathrm{R}^{2}$ value generally established the adequacy of the model [Eq. (2)] to explain the response (BPT $\mathrm{Braq}_{\text {raq }}$ ) from the 
Table 8 . The classified aquifer productivity potential zones and their areas extent coverages.

\begin{tabular}{ccc}
\hline APMI & Classifications & Areal Coverage $\mathbf{~ K m}^{\mathbf{2}} \mathbf{( \% )}$ \\
\hline $0.2246-1.8096$ & Low & $737.79(26)$ \\
$1.8096-2.5749$ & Low - medium & $571.52(20)$ \\
$2.5749-3.2775$ & Medium & $1074.11(38)$ \\
$3.2775-4.4897$ & Medium - high & $464.38(16)$ \\
\hline
\end{tabular}

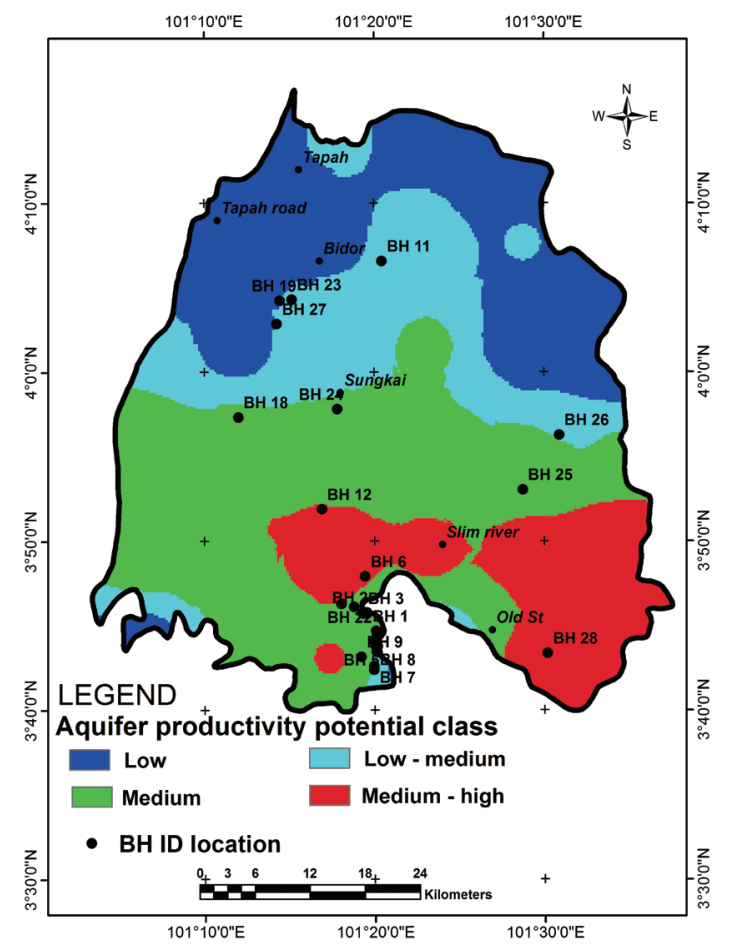

Fig. 9. GRPPM map based on the combined aquifer hydraulic parameter. (Color online only)

predictor (TR). However, the predictive power accuracy of the model [Eq. (2)] is essential to establish its validity in predicting aquifer transmissivity property at any location where no pumping test record or no boreholes exist. The model forecast method proposed by Koutsoyiannis (1977) and Neil (1990) as used by Mogaji et al. (2015) was adopted to validate the predictive power accuracy of the model. The value of factor $\mathrm{K}_{\mathrm{h}}$ for measuring the model prediction power accuracy was computed based on the Theil inequality coefficient given the following equation:

$\mathrm{K}_{\mathrm{h}}=\sum_{\mathrm{i}=1}^{\mathrm{n}}\left(\frac{\mathrm{BPT}_{\text {Traq }_{\mathrm{i}}}-\widehat{\mathrm{Tr}}}{\widehat{\mathrm{Tr}}}\right)^{2}$

The given $\mathrm{BPT}_{\text {Traq }}$ and $\mathrm{Tr}$ records (columns 4 and 9 of Table 2) were used in Eq. (13). The accuracy appraisal result of the proposed ATPP model is shown in Table 9. Ac- cording to Neil (2003), the smaller the value of $K_{h}=3.8515$ compared with the $\chi^{2}$-tabulated value $=17.70$, the better the prediction accuracy of this model. Based on this condition, the result presented in Table 9 confirmed the reliability and accuracy of using the established ATPP model [Eq. (2)] to predict aquifer transmissivity from geophysical measurements at any location even in areas without boreholes. The established adequacy of the model based on the $\mathrm{R}^{2}$ values result obtained from the linear regression technique application and the obtained reliability and accuracy results based on the applied Theil inequality coefficient approach further validates the applicability of the developed ATPP model [Eq. (2)] for the area.

Furthermore, the GRPPM map (Fig. 9) for the area was equally validated to establish its reliability and usefulness in environmental decision-making studies. According to Jha et al. (2010), the most appropriate method for this validation would have been the step-drawdown tests at various locations within each delineated zone to determine locationspecific safe aquifer yields. However, in the absence of such data, the well discharge data or well yield data were widely used by several researchers as alternative validation indices with satisfactory results (Edet and Okereke 1997; Jha and Peiffer 2006; Jha et al. 2007; Prasad et al. 2008; Saud 2010; Elewa et al. 2010; Jha et al. 2010). Previous studies considered the well yield data because the borehole yield is the most effective way through which accurate information on the aquifer conditions in an area is obtained. Consequently, this study assessed the accuracy of the produced GRPPM map using the borehole well yield data obtained from the Malaysian Department of Minerals and Geosciences for its validation. The analyzed well yield record for the available 28 drilled holes in the area provides the well yield values in the range of $0.39-43.71 \mathrm{~m}^{3} \mathrm{~h}^{-1}$ (column 4 , Table 1) with a mean value of $17.72 \mathrm{~m}^{3} \mathrm{~h}^{-1}$ by applying the SPSS software package. Based on the JMG (2007) classification approach, the actual yield description for the area is $0.39-17 \mathrm{~m}^{3} \mathrm{~h}^{-1}$ (low), $17-30 \mathrm{~m}^{3} \mathrm{~h}^{-1}$ (medium), and $>30 \mathrm{~m}^{3} \mathrm{~h}^{-1}$ (high), which were obtained from the borehole well yield data provided by the Malaysian Department of Minerals and Geosciences. Based on the borehole locations, the expected borehole yield descriptions from the prediction map (column 4), the actual yield descriptions obtained from the pumping tests (column 6), and the coincidence or not-coincidence between the expected/actual borehole yield descriptions (column 7) in Table 10, the accuracy assessment of the GRPPM map (Fig. 9) is as follows:

Total number of boreholes available $=28$

Number of boreholes where the expected and actual yield classifications coincide $=20$

Number of boreholes where the expected and actual yield classifications do not coincide $=8$

Success rate (accuracy) of the prediction $=20 / 28 \times 100=$ $71.43 \%$ 
Table 9. Aquifer transmissivity parameter predictive (ATPP) model prediction accuracy analysis.

\begin{tabular}{cccc}
\hline Proposed transmissivity parameter predictive model & Nos of 2D locations & $\boldsymbol{\chi}_{\boldsymbol{p}}{ }^{2}, \boldsymbol{\alpha}=\mathbf{5 \%}$ & $\mathbf{K}_{\mathbf{h}}$ - value \\
\hline $\mathrm{BPT}_{\text {Trap }}=0.1589(\mathrm{TR})-268.61$ & 30 & 17.70 & 3.8515 \\
\hline
\end{tabular}

Table 10. Validation table for the produced groundwater reservoir (aquifer) productivity potential model.

\begin{tabular}{|c|c|c|c|c|c|c|}
\hline \multirow{2}{*}{$\begin{array}{l}\text { Borehole } \\
\text { Numbers }\end{array}$} & \multicolumn{2}{|c|}{ Observation Coordinates } & \multirow{2}{*}{$\begin{array}{l}\text { Expected yield description from } \\
\text { the prediction map }\end{array}$} & \multirow{2}{*}{$\begin{array}{l}\text { Actual yield from the drilled } \\
\text { borehole }\left(\mathrm{m}^{3} \mathbf{h}^{-1}\right)\end{array}$} & \multirow{2}{*}{$\begin{array}{l}\text { Actual yield } \\
\text { description }\end{array}$} & \multirow{2}{*}{ Remarks } \\
\hline & LAT & LONG & & & & \\
\hline 1 & 3.762378 & 101.3271 & Medium & 17 & Low & Not - Coincide \\
\hline 2 & 3.76354 & 101.3267 & Medium & 18 & Medium & Coincide \\
\hline 3 & 3.762735 & 101.3226 & Medium & 18.7 & Medium & Coincide \\
\hline 4 & 3.730068 & 101.3373 & Low - Medium & 14 & Low & Coincide \\
\hline 5 & 3.7301 & 101.3362 & Low - Medium & 14 & Low & Coincide \\
\hline 6 & 3.799 & 101.325 & Medium- - High & 21 & Medium & Coincide \\
\hline 7 & 3.70711 & 101.3339 & Low - Medium & 14.7 & Low & Coincide \\
\hline 8 & 3.710496 & 101.3339 & Low - Medium & 16.29 & Low & Coincide \\
\hline 9 & 3.719829 & 101.3214 & Medium & 10.72 & Low & Not - Coincide \\
\hline 10 & 3.76241 & 101.3233 & Medium & 6.9 & Low & Not - Coincide \\
\hline 11 & 4.113 & 101.337 & Low - Medium & 40 & High & Not - Coincide \\
\hline 12 & 3.836776 & 101.3313 & Medium - High & 19.63 & Medium & Coincide \\
\hline 13 & 3.74509 & 101.3358 & Low - Medium & 14.06 & Low & Coincide \\
\hline 14 & 3.740059 & 101.3365 & Low - Medium & 2.48 & Low & Coincide \\
\hline 15 & 3.724937 & 101.3362 & Low - Medium & 13.86 & Low & Coincide \\
\hline 16 & 3.724252 & 101.3371 & Low - Medium & 14.01 & Low & Coincide \\
\hline 17 & 3.769023 & 101.3141 & Medium & 20.4 & Medium & Coincide \\
\hline 18 & 3.956 & 101.201 & Medium & 26.5 & Medium & Coincide \\
\hline 19 & 4.71 & 101.242 & Low & 43.71 & High & Not - Coincide \\
\hline 20 & 3.734592 & 101.3346 & Low - Medium & 18.34 & Low & Coincide \\
\hline 21 & 3.729502 & 101.3357 & Low - Medium & 13.97 & Low & Coincide \\
\hline 22 & 3.772 & 101.302 & Medium & 24.41 & Medium & Coincide \\
\hline 23 & 3.773505 & 101.319 & Medium & 20 & Medium & Coincide \\
\hline 24 & 3.964 & 101.298 & Medium & 33.7 & High & Not - Coincide \\
\hline 25 & 3.884519 & 101.4799 & Medium & 14.6 & Low & Not - Coincide \\
\hline 26 & 3.938435 & 101.5157 & Low - Medium & 16.6 & Low & Coincide \\
\hline 27 & 4.048 & 101.239 & Low & 0.39 & Low & Coincide \\
\hline 28 & 3.723188 & 101.504 & Medium - High & 8.67 & Low & Not - Coincide \\
\hline
\end{tabular}

The prediction success rate (accuracy) shows that a GIS-based combined modeling of aquifer hydraulic parameters obtained from the geophysical measurement produced a viable prediction model that enhanced decision making in groundwater resource development.

\section{CONCLUSION}

A desk study combining geophysical measurements and borehole data analysis is a key approach to provide excellent information in evaluating the hydrological condi- tions in an area. This study conducted $2 \mathrm{D}$ resistivity imaging data and BPT results analysis in the southern part of Perak involving $2 \mathrm{D}$ resistivity imaging data and BPT results interpretation. The DZP, developed from the interpreted geoelectrical parameters, were modeled with the $\mathrm{BPT}_{\text {Traq }}$ to develop the proposed ATPP model with a high correlation coefficient of 0.85 . When the Theil inequality coefficient measurement analysis is applied, the reliability and prediction power accuracy analyses of the proposed ATPP model was established using the $\chi^{2}$ distribution at $\alpha=0.05$ significance level through $\mathrm{R}$ software application. Based on the 
developed ATPP model, the equations for the GHP properties for feasible aquifer hydraulic parameters determination, namely, $\operatorname{Tr}, \mathrm{K}, \mathrm{S}_{\mathrm{t}}$, and $\mathrm{D}$, were established for the area. The estimated results from the GHP equations application were used to generate four APPCF thematic maps. The results of the produced APPCF maps were synthesized through GISbased AHP technique application to prepare a prediction model for groundwater reservoir productivity potential in the area. With the AHP method, the weighing and integration of these APPCF maps were conducted in the order of their relative importance to the aquifer productivity potentiality in the study area. Using the weight linear combination, the estimated normalized weight and rating (R) of the map spatial attributes, the APMI model of the area was developed and used for values estimation of APMI scores at each grid center established. The APMI results were processed in the GIS environment to produce a GRPPM map for the study area. The produced GRPPM revealed four distinct potential zones such as low, low-medium, medium, and medium-high with the low and medium/high potential zones having a percentage area coverage extent of 46 and 54\%, respectively. The GRPPM map validation result using the field-measured in situ groundwater well yield result established $71.43 \%$ prediction accuracy.

The results obtained from this study show that the developed ATPP model and the produced GRPPM map based on 2D imaging geophysical technique and borehole data analysis integration significantly enhanced the decision accuracy in groundwater resource development. The developed ATPP model and established GHP model equations can be used to estimate aquifer hydraulic parameters in an area with similar geology even where no drill boreholes exist.

Acknowledgements This project was conducted using the financial support from RUI (Investigation of the impacts of summertime monsoon circulation to aerosol transportation and distribution in Southeast Asia, which can lead to global climate change, 1001/PFIZIK/811228). The authors are also grateful to Universiti Sains Malaysia for providing a one-year, post-doctoral fellowship to Dr. Kehinde Anthony Mogaji (BW001607). Special appreciation also goes to the Federal University of Technology Akure, Nigeria for granting the study leave utilized to conduct this study.

\section{REFERENCES}

Adiat, K. A. N., M. N. M. Nawawi, and K. Abdullah, 2012: Assessing the accuracy of GIS-based elementary multi criteria decision analysis as a spatial prediction tool - A case of predicting potential zones of sustainable groundwater resources. J. Hydrol., 440-441, 75-89, doi: 10.1016/j.jhydrol.2012.03.028. [Link]

Adiat, K. A. N., M. N. M. Nawawi, and K. Abdullah, 2013: Application of multi-criteria decision analysis to geo- electric and geologic parameters for spatial prediction of groundwater resources potential and aquifer evaluation. Pure Appl. Geophys., 170, 453-471, doi: 10.1007/ s00024-012-0501-9. [Link]

Ahmed,S. and G. de Marsily, 1987: Comparison of geostatistical methods for estimating transmissivity using data on transmissivity and specific capacity. Water Resour. Res., 23, 1717-1737, doi: 10.1029/WR023i009p01717. [Link]

Ariff, H., M. S. Salit, N. Ismail, and Y. Nukman, 2008: Use of analytical hierarchy process (AHP) for selecting the best design concept. J. Teknologi, 49, 1-18, doi: 10.11113/jt.v49.188. [Link]

Asry, Z., A. R. Samsudin, W. Z. Yaacob, and J. Yaakub, 2012: Groundwater investigation using electrical resistivity imaging technique at Sg. Udang, Melaka, Malaysia. Bull. Geol. Soc. Malaysia, 58, 55-58.

Awasthi, A. and S. S. Chauhan, 2011: Using AHP and Dempster-Shafer theory for evaluating sustainable transport solutions. Environ. Model. Software, 26, 787 796, doi: 10.1016/j.envsoft.2010.11.010. [Link]

Chan, F. T. S., N. Kumar, M. K. Tiwari, H. C. W. Lau, and K. L. Choy, 2008: Global supplier selection: A fuzzyAHP approach. Int. J. Prod. Res., 46, 3825-3857, doi: 10.1080/00207540600787200. [Link]

Chen, J., S. Hubbard, and Y. Rubin, 2001: Estimating the hydraulic conductivity at the south oyster site from geophysical tomographic data using Bayesian techniques based on the normal linear regression model. Water Resour. Res., 37, 1603-1613, doi: 10.1029/2000WR900392. [Link]

Chowdhury, A., M. K. Jha, V. M. Chowdary, and B. C. Mal, 2009: Integrated remote sensing and GIS-based approach for assessing groundwater potential in West Medinipur district, West Bengal, India. Int. J. Remote Sens., 30, 231-250, doi: 10.1080/01431160802270131. [Link]

De Araújo, C. C. and A. B. Macedo, 2002: Multicriteria geologic data analysis for mineral favorability mapping: Application to a metal sulphide mineralized area, Ribeira Valley Metallogenic Province, Brazil. Nat. Resour. Res., 11, 29-43, doi: 10.1023/A:1014235703541. [Link]

Dweiri, F. and F. M. Al-Oqla, 2006: Material selection using analytical hierarchy process. Int. J. Comput. Appl. Tech., 26, 182-189, doi: 10.1504/IJCAT.2006.010763. [Link]

Edet, A. E. and C. S. Okereke, 1997: Assessment of hydrogeological conditions in basement aquifers of the Precambrian Oban massif, southeastern Nigeria. $J$. Appl. Geophys., 36, 195-204, doi: 10.1016/S09269851(96)00049-3. [Link]

Ekwe, A. C., N. N. Onu, and K. M. Onuoha, 2006: Estimation of aquifer hydraulic characteristics from electrical 
sounding data: The case of middle Imo River basin aquifers, south-eastern Nigeria. J. Spatial Hydrol., 6, 121-132.

Ekwe, A. C., I. N. Nnodu, K. I. Ugwumbah, and O. S. Onwuka, 2010: Estimation of aquifer hydraulic characteristics of low permeability formation from geosounding data: A case study of Oduma town, Enugu State. Online J. Earth Sci., 4, 19-26, doi: 10.3923/ojesci.2010.19.26. [Link]

Elewa, H. H., R. G. Fathy, and A. A. Qaddah, 2010: The contribution of geographic information systems and remote sensing in determining priority areas for hydrogeological development, Darb el-Arbain area, Western Desert, Egypt. Hydrogeol. J., 18, 1157-1171, doi: 10.1007/s10040-010-0590-4. [Link]

Ewusi, A., J. S. Kuma, and H. J. Voigt, 2009: Utility of the 2-D multi-electrode resistivity imaging technique in groundwater exploration in the Voltaian sedimentary basin, Northern Ghana. Nat. Resour. Res., 18, 267-275, doi: 10.1007/s1 1053-009-9102-4. [Link]

Ezeh, C. C., G. Z. Ugwu, A. Okonkwo, and J. Okamkpa, 2013: Using the relationships between geoelectrical and hydrogeological parameters to assess aquifer productivity in Udi LGA, Enugu State, Nigeria. IRJGM, 3, 9-18.

Fashae, O. A., M. N. Tijani, A. O. Talabi, and O. I. Adedeji, 2014: Delineation of groundwater potential zones in the crystalline basement terrain of SW-Nigeria: An integrated GIS and remote sensing approach. Appl. Water Sci., 4, 19-38, doi: 10.1007/s13201-013-0127-9. [Link]

Feizizadeh, B., T. Blaschke, and H. Nazmfar, 2014: GISbased ordered weighted averaging and Dempster-Shafer methods for landslide susceptibility mapping in the Urmia Lake Basin, Iran. Int. J. Digital Earth, 7, 688708, doi: 10.1080/17538947.2012.749950. [Link]

Ghamgosar, M., M. Haghyghy, F. Mehrdoust, and N. Arshad, 2011: Multicriteria decision making based on analytical hierarchy process (AHP) in GIS for tourism. Middle-East J. Sci. Res., 10, 501-507.

He, B., Y. Cui, C. Chen, J. Chen, and Y. Liu, 2011: Uncertainty mapping method for mineral resources prospectivity integrating multi-source geology spatial data sets and evidence reasoning model. 2011 19th International Conference on Geoinformatics, IEEE, 5 pp, doi: 10.1109/GeoInformatics.2011.5980788. [Link]

Heigold, P. C., R. H. Gilkeson, K. Cartwright, and P. C. Reed, 1979: Aquifer transmissivity from surficial electrical methods. Groundwater, 17, 338-345, doi: 10.1111/j.1745-6584.1979.tb03326.x. [Link]

Hiscock, K. M., 2005: Hydrogeology: Principles and Practice, Wiley-Blackwell, Oxford, $406 \mathrm{pp}$.

Ho, W., 2008: Integrated analytic hierarchy process and its applications - A literature review. Eur. J. Oper. Res., 186, 211-228, doi: 10.1016/j.ejor.2007.01.004. [Link]
Islami, N., S. H. Taib, I. Yusoff, and A. A. Ghani, 2012: Integrated geoelectrical resistivity, hydrochemical and soil property analysis methods to study shallow groundwater in the agriculture area, Machang, Malaysia. Environ. Earth Sci., 65, 699-712, doi: 10.1007/ s12665-011-1117-6. [Link]

Janssen, R., 1992: Multiobjective Decision Support for Environmental Management, Springer Netherlands, 233 pp, doi: 10.1007/978-94-011-2807-0. [Link]

Jha, M. K. and S. Peiffer, 2006: Applications of Remote Sensing and GIS Technologies in Groundwater Hydrology: Past, Present and Future, BayCEER, Bayreuth, Germany, $201 \mathrm{pp}$.

Jha, M. K., A. Chowdhury, V. M. Chowdary, and S. Peiffer, 2007: Groundwater management and development by integrated remote sensing and geographic information systems: prospects and constraints. Water Resour. Manag., 21, 427-467, doi: 10.1007/s11269-006-90244. [Link]

Jha, M. K., V. M. Chowdary, and A. Chowdhury, 2010: Groundwater assessment in Salboni Block, West Bengal (India) using remote sensing, geographical information system and multi-criteria decision analysis techniques. Hydrogeol. J., 18, 1713-1728, doi: 10.1007/ s10040-010-0631-z. [Link]

JMG, 2007: Hydrogeological map of Selangor and Kuala Lumpur Federal Territory, Scale 1:250,000.

Mohamed, S. E. J., S. Ibrahim, W. N. A. Sulaiman, and P. A. Latif, 2013: Groundwater resources assessment using integrated geophysical techniques in the southwestern region of Peninsular Malaysia. Arab. J. Geosci., 6, 4129-4144, doi: 10.1007/s12517-012-0700-9. [Link]

Kaliraj, S., N. Chandrasekar, and N. S. Magesh, 2014: Identification of potential groundwater recharge zones in Vaigai upper basin, Tamil Nadu, using GIS-based analytical hierarchical process (AHP) technique. Arab. J. Geosci., 7, 1385-1401, doi: 10.1007/s12517-0130849-x. [Link]

Kelly, W. E., 1977: Geoelectric sounding for estimating aquifer hydraulic conductivity. Groundwater, 15, 420425, doi: 10.1111/j.1745-6584.1977.tb03189.x. [Link]

Khalil, M. A., F. M. Santos, M. Cachão, P. E. Fonseca, and J. Mata, 2013: 2D and 3D resistivity tomography of the Suímo garnet-bearing dyke, Lisbon Volcanic Complex, Portugal: A case study. J. Geophys. Eng., 10, doi: 10.1088/1742-2132/10/3/035013. [Link]

Khan, A. A., S. H. Akhter, M. A. Hasan, and K. M. Ahmed, 2002: VES signatures in soft rock groundwater exploration vis-à-vis geoenvironmental implications. In: Singh, V. P., M. Al-Rashed, and M. M. Sherif (Eds.), Proceedings of the International Conference on Water Resources Management in Arid Regions (WaRMAR): Volume 2 - Groundwater Hydrology, Balkema Publishers, Leiden, 179-193. 
Koefoed, O., 1979: Geosounding Principles 1: Resistivity Sounding Measurements, Elsevier Scientific Publishing Company, Amsterdam, 276 pp.

Koutsoyiannis, A., 1977: Theory of Econometrics: An Introductory Exposition of Econometric Methods, Macmillan Education Limited, 681 pp.

Kumar, M. S., D. Gnanasundar, and L. Elango, 2001: Geophysical studies to determine hydraulic characteristics of an alluvial aquifer. J. Environ. Hydrol., 9, 1-8.

Lahdelma, R., P. Salminen, and J. Hokkanen, 2000: Using multicriteria methods in environmental planning and management. Environ. Manage., 26, 595-605, doi: 10.1007/s002670010118. [Link]

Lee, S., K. Y. Song, Y. Kim, and I. Park, 2012: Regional groundwater productivity potential mapping using a geographic information system (GIS) based artificial neural network model. Hydrogeol. J., 20, 1511-1527, doi: 10.1007/s10040-012-0894-7. [Link]

Linkov, I., F. K. Satterstrom, G. Kiker, C. Batchelor, T. Bridges, and E. Ferguson, 2006: From comparative risk assessment to multi-criteria decision analysis and adaptive management: Recent developments and applications. Environ. Int., 32, 1072-1093, doi: 10.1016/j. envint.2006.06.013. [Link]

Lohman, S. W., 1972: Ground-Water Hydraulics, Geological Survey Professional Paper 708, United States Government Printing Office, Washington, $70 \mathrm{pp}$.

Loke, M. H., 2001: The use of 3-D electrical imaging surveys for mapping complex subsurface structures. Proceedings of Geological Society of Malaysia Seminar on the Recent Advances in Engineering Geophysics, Kuala Lumpur, 47-59.

Loke, M. H., 2004: Geoelectrical imaging 2D \& 3D Geotomo Software, Malaysia.

Loke, M. H. and R. D. Barker, 1996: Rapid least-squares inversion of apparent resistivity pseudosections by a quasi-Newton method. Geophys. Prospect., 44, 131152, doi: 10.1111/j.1365-2478.1996.tb00142.x. [Link]

Loke, M. H., I. Acworth, and T. Dahlin, 2003: A comparison of smooth and blocky inversion methods in 2D electrical imaging surveys. Explor. Geophys., 34, 182187, doi: 10.1071/EG03182. [Link]

Maillet, R., 1947: The fundamental equations of electrical prospecting. Geophysics, 12, 529-556, doi: 10.1190/1.1437342. [Link]

Minerals and Geoscience Department, Malaysia, 2004: Impact of the 26th December 2004 Tsunami on Groundwater Systems and Groundwater Based Water Supplies in Malaysia.

Mogaji, K. A., H. S. Lim, and K. Abdullah, 2014: Modeling groundwater vulnerability prediction using geographic information system (GIS)-based ordered weighted average (OWA) method and DRASTIC model theory hybrid approach. Arab. J. Geosci., 7, 5409-5429, doi: 10.1007/s12517-013-1163-3. [Link]

Mogaji, K. A., H. S. Lim, and K. Abdullah, 2015: Modeling of groundwater recharge using a multiple linear regression (MLR) recharge model developed from geophysical parameters: A case of groundwater resources management. Environ. Earth Sci., 73, 1217-1230, doi: 10.1007/s12665-014-3476-2. [Link]

Montazar, A. and S. M. Behbahani, 2007: Development of an optimised irrigation system selection model using analytical hierarchy process. Biosystems Eng., 98, 155-165, doi: 10.1016/j.biosystemseng.2007.06.003. [Link]

Nath, S. K, H. P. Patra, and S. Shahid, 2000: Geophysical Prospecting for Ground Water, Oxford and IBH Publishing, New Delhi.

Ndatuwong, L. G. and G. S. Yadav, 2015: Application of geo-electrical data to evaluate groundwater potential zone and assessment of overburden protective capacity in part of Sonebhadra district, Uttar Pradesh. Environ. Earth Sci., 73, 3655-3664, doi: 10.1007/s12665-0143649-z. [Link]

Neil, H. T., 1990: Multivariate Analysis with Application in Education and Psychology, 2nd edition, Wiley, New York.

Neil, H. T., 2003: Multivariate Analysis with Application in Education and Psychology, Revised edition, Wadsworth publishing Company Inc, Belmont.

Neshat, A., B. Pradhan, S. Pirasteh, and H. Z. M. Shafri, 2014: Estimating groundwater vulnerability to pollution using a modified DRASTIC model in the Kerman agricultural area, Iran. Environ. Earth Sci., 71, 31193131, doi: 10.1007/s12665-013-2690-7. [Link]

Niwas, S. and D. C. Singhal, 1981: Estimation of aquifer transmissivity from Dar-Zarrouk parameters in porous media. J. Hydrol., 50, 393-399, doi: 10.1016/00221694(81)90082-2. [Link]

Oborie, E. and G. J. Udom, 2014: Determination of aquifer transmissivity using geoelectrical sounding and pumping test in parts of Bayelsa State, Nigeria. Peak J. Phys. Environ. Sci. Res., 2, 32-40.

Pazand, K., A. Hezarkhani, and M. Ataei, 2012: Using TOPSIS approaches for predictive porphyry $\mathrm{Cu}$ potential mapping: A case study in Ahar-Arasbaran area (NW, Iran). Comput. Geosci., 49, 62-71, doi: 10.1016/j.cageo.2012.05.024. [Link]

Prasad, R. K., N. C. Mondal, P. Banerjee, M. V. Nandakumar, and V. S. Singh, 2008: Deciphering potential groundwater zone in hard rock through the application of GIS. Environ. Geol., 55, 467-475, doi: 10.1007/ s00254-007-0992-3. [Link]

Pujari, P. R. and A. K. Soni, 2009: Sea water intrusion studies near Kovaya limestone mine, Saurashtra coast, India.Environ.Monit.Assess., 154,93-109, doi: 10.1007/ s10661-008-0380-9. [Link] 
Regan, H. M., F. W. Davis, S. J. Andelman, A. Widyanata, and M. Freese, 2007: Comprehensive criteria for biodiversity evaluation in conservation planning. Biodivers. Conserv., 16, 2715-2728, doi: 10.1007/s10531-0069100-3. [Link]

Rubin, Y. and S. S. Hubbard, 2005: Hydrogeophysics, Springer Netherlands, Dordrecht, 527 pp, doi: 10.1007/1-4020-3102-5. [Link]

Saaty, T. L., 1980: The Analytic Hierarchy Process: Planning, Priority Setting, Resource Allocation, McGrawHill, New York, 287 pp.

Sasaki, Y., 1992: Resolution of resistivity tomography inferred from numerical simulation. Geophys. Prospect., 40, 453-463, doi: 10.1111/j.1365-2478.1992. tb00536.x. [Link]

Sathish, S., L. Elango, R. Rajesh, and V. S. Sarma, 2011: Assessment of seawater mixing in a coastal aquifer by high resolution electrical resistivity tomography. Int. J. Environ. Sci. Tech., 8, 483-492, doi: 10.1007/ BF03326234. [Link]

Satpathy, B. N. and D. N. Kanungo, 1976: Groundwater exploration in hard-rock terrain-A case history. Geophys. Prospect., 24, 725-736, doi: 10.1111/j.13652478.1976.tb01569.x. [Link]

Sattar, G. S., M. Keramat, and S. Shahid, 2016: Deciphering transmissivity and hydraulic conductivity of the aquifer by vertical electrical sounding (VES) experiments in Northwest Bangladesh. Appl. Water Sci., 6, 35-45, doi: 10.1007/s13201-014-0203-9. [Link]

Saud, M. A., 2010: Mapping potential areas for groundwater storage in Wadi Aurnah Basin, western Arabian Peninsula, using remote sensing and geographic information system techniques. Hydrogeol. J., 18, 1481-1495, doi: 10.1007/s 10040-010-0598-9. [Link]

Schimschal, U., 1981: Flowmeter analysis at raft river, Idaho. Groundwater, 19, 93-97, doi: 10.1111/j.17456584.1981.tb03443.x. [Link]

Soupios, P. M., M. Kouli, F. Vallianatos, A. Vafidis, and G. Stavroulakis, 2007: Estimation of aquifer hydraulic parameters from surficial geophysical methods: A case study of Keritis Basin in Chania (Crete Greece). J. Hydrol., 338, 122-131, doi: 10.1016/j.jhydrol.2007.02.028. [Link]

Srivastava, P. K. and A. K. Bhattacharya, 2006: Groundwater assessment through an integrated approach using remote sensing, GIS and resistivity techniques: A case study from a hard rock terrain. Int. J. Remote Sens., 27, 4599-4620, doi: 10.1080/01431160600554983. [Link]

Tecle, A. and L. Duckstein, 1994: Concepts of multi-criteria decision making. In: Bogardi, J. J. and H. P. Nachtneb- el (Eds.), Multicriteria Analysis in Water Resources Management, UNESCO, Paris, 33-62.

Thirumalaivasan, D., M. Karmegam, and K. Venugopal, 2003: AHP-DRASTIC: Software for specific aquifer vulnerability assessment using DRASTIC model and GIS. Environ. Model. Software, 18, 645-656, doi: 10.1016/S1364-8152(03)00051-3. [Link]

Tizro, A. T. and D. C. Singhal, 1993: Geoelectrical studies in Narnaul area for estimating transmissivity in alluvial aquifers. National Seminar on Hydrological Hazards, University of Roorkee, India.

Tizro, A. T., K. S. Voudouris, and M. Eini, 2007: Groundwater balance, safe yield and recharge feasibility in a semi-arid environment: A case study from western part of Iran. J. Appl. Sci., 7, 2967-2976, doi: 10.3923/ jas.2007.2967.2976. [Link]

Tizro, A. T., K. S. Voudouris, M. Salehzade, and H. Mashayekhi, 2010: Hydrogeological framework and estimation of aquifer hydraulic parameters using geoelectrical data: A case study from West Iran. Hydrogeol. J., 18, 917-929, doi: 10.1007/s10040-010-0580-6. [Link]

Ugada, U., K. K. Ibe, C. Z. Akaolisa, and A. I. Opara, 2014: Hydrogeophysical evaluation of aquifer hydraulic characteristics using surface geophysical data: A case study of Umuahia and environs, Southeastern Nigeria. Arab. J. Geosci., 7, 5397-5408, doi: 10.1007/s12517013-1150-8. [Link]

Vahidnia, M. H., A. A. Alesheikh, and A. Alimohammadi, 2009: Hospital site selection using fuzzy AHP and its derivatives. J. Environ. Manage., 90, 3048-3056, doi: 10.1016/j.jenvman.2009.04.010. [Link]

Vozoff, K. and D. L. B. Jupp, 1975: Joint inversion of geophysical data. Geophys. J. Int., 42, 977-991, doi: 10.1111/j.1365-246X.1975.tb06462.x. [Link]

Yal, G. P. and H. Akgün, 2013: Landfill site selection and landfill liner design for Ankara, Turkey. Environ. Earth Sci., 70, 2729-2752, doi: 10.1007/s12665-0132334-y. [Link]

Ying, X., G. M. Zeng, G. Q. Chen, L. Tang, K. L. Wang, and D. Y. Huang, 2007: Combining AHP with GIS in synthetic evaluation of eco-environment quality - A case study of Hunan Province, China. Ecol. Model., 209, 97-109, doi: 10.1016/j.ecolmodel.2007.06.007. [Link]

Zhou, L. and Y. Chen, 2014: Exploring the potential of community-based grassland management in Yanchi County of Ningxia Hui Autonomous Region, China: An application of the SWOT-AHP method. Environ. Earth Sci., 72, 1811-1820, doi: 10.1007/s12665-0143090-3. [Link] 